\title{
Depolarization ratio of polar stratospheric clouds in coastal Antarctica: comparison analysis between ground-based Micro Pulse Lidar and space-borne CALIOP observations
}

\author{
C. Córdoba-Jabonero ${ }^{1}$, J. L. Guerrero-Rascado ${ }^{2,3}$, D. Toledo ${ }^{1}$, M. Parrondo ${ }^{1}$, M. Yela ${ }^{1}$, M. Gil ${ }^{1}$, and H. A. Ochoa ${ }^{4}$ \\ ${ }^{1}$ Instituto Nacional de Técnica Aeroespacial (INTA), Atmospheric Research and Instrumentation Branch, Torrejón de Ardoz, \\ 28850, Madrid, Spain \\ ${ }^{2}$ Andalusian Center for Environmental Research (CEAMA), Group of Atmospheric Physics, Universidad de Granada-Junta \\ de Andalucía, Granada, Spain \\ ${ }^{3}$ Universidad de Granada (UGR), Department of Applied Physics, Granada, Spain \\ ${ }^{4}$ Dirección Nacional del Antártico/Instituto Antártico Argentino (DNA/IAA), Buenos Aires, Argentina \\ Correspondence to: C. Córdoba-Jabonero (cordobajc@inta.es)
}

Received: 28 September 2012 - Published in Atmos. Meas. Tech. Discuss.: 31 October 2012

Revised: 21 February 2013 - Accepted: 21 February 2013 - Published: 14 March 2013

\begin{abstract}
Polar stratospheric clouds (PSCs) play an important role in polar ozone depletion, since they are involved in diverse ozone destruction processes (chlorine activation, denitrification). The degree of that ozone reduction is depending on the type of PSCs, and hence on their occurrence. Therefore PSC characterization, mainly focused on PSC-type discrimination, is widely demanded. The backscattering $(R)$ and volume linear depolarization $\left(\delta^{\mathrm{V}}\right)$ ratios are the parameters usually used in lidar measurements for PSC detection and identification. In this work, an improved version of the standard NASA/Micro Pulse Lidar (MPL-4), which includes a built-in depolarization detection module, has been used for PSC observations above the coastal Antarctic Belgrano II station (Argentina, $77.9^{\circ} \mathrm{S} 34.6^{\circ} \mathrm{W}, 256 \mathrm{~m}$ a.s.1.) since 2009. Examination of the MPL- $4 \delta^{\mathrm{V}}$ feature as a suitable index for PSC-type discrimination is based on the analysis of the twochannel data, i.e., the parallel (p-) and perpendicular (s-) polarized MPL signals. This study focuses on the comparison of coincident $\delta \mathrm{V}^{\mathrm{V}}$-profiles as obtained from ground-based MPL4 measurements during three Antarctic winters with those reported from the space-borne lidar CALIOP (Cloud-Aerosol Lidar with Orthogonal Polarization) aboard the CALIPSO (Cloud-Aerosol Lidar and Infrared Pathfinder Satellite Observation) satellite in the same period (83 simultaneous cases are analysed for 2009-2011 austral winter times). Three different approaches are considered for the comparison analysis
\end{abstract}

between both lidar profile data sets in order to test the degree of agreement: the correlation coefficient (CC), as a measure of the relationship between both PSC vertical structures; the mean differences together with their root mean square (RMS) values found between data sets; and the percentage differences (BIAS), parameter also used in profiling comparisons between CALIOP and other ground-based lidar systems. All of them are examined as a function of the CALIPSO groundtrack distance from the Belgrano II station. Results represent a relatively good agreement between both ground-based MPL-4 and space-borne CALIOP profiles of the volume linear depolarization ratio $\delta^{\mathrm{V}}$ for PSC events, once the MPL-4 depolarization calibration parameters are applied. Discrepancies between CALIOP and MPL-4 profiles in vertical layering structure are enhanced from $20 \mathrm{~km}$ up, likely due to a decrease of the signal-to-noise ratio (SNR) for both lidar systems at those altitudes. Regarding the results obtained from the mean and the percentage differences found between MPL-4 and CALIOP $\delta^{\mathrm{V}}$ profiles, a predominance of negative values is also observed, indicating a generalized underestimation of the MPL-4 depolarization as compared to that reported by CALIOP. However, absolute differences between those $\delta^{\mathrm{V}}$-profile data sets are no higher than a $10 \pm 11 \%$ in average. Moreover, the degree of agreement between both lidar $\delta^{\mathrm{V}}$ data sets is slightly dependent on the CALIPSO groundtrack overpass distance from the Belgrano II station. That 
is, small discrepancies are found when CALIPSO groundtrack distance is as close as far from the ground-based station. These results would indicate that MPL-4 depolarization observations would reflect relatively well the PSC field that CALIOP can detect at relatively large distances from the ground-based station. As a consequence, PSC properties can be statistically similar, on average, over large volumes, and hence the present weak disagreement found between both the lidar $\delta^{\mathrm{V}}$ data sets can be likely dominated by small spatial PSC inhomogeneities along the CALIPSO separation from the station. This statement is based on the fact that Belgrano II is a station located well inside the stable Antarctic polar vortex, allowing determined thermodynamic conditions leading to a very low variability in the PSC field, and in their properties.

\section{Introduction}

The polar stratosphere in both hemispheres is characterized by very low temperatures during winter leading to the formation of polar stratospheric clouds (PSC). Heterogeneous chemical reactions occur on the surface of the PSCs, activating destructive compounds of ozone. Ozone destruction processes, through direct chlorine activation or indirectly through denitrification, are straight linked to the presence of a given type of PSC, and hence influencing the degree of ozone depletion (Solomon, 1999). In Polar regions PSCs start to form during winter at stratospheric temperatures below the condensation threshold of the nitric acid trihydrate (NAT), depending on the water vapor and nitric acid partial pressure (Hanson and Mauersberger, 1988). PSCs are classified in three main groups depending on their composition, and then on their temperature formation threshold (i.e., see the review on PSC microphysics and chemistry by Lowe and MacKenzie, 2008, and references therein): type Ia (PSC-Ia) are nitric acid trihydrate (NAT) clouds formed above the frost point $\left(T_{\mathrm{NAT}}=194 \mathrm{~K}\right.$ at $\left.30 \mathrm{hPa}\right)$, type $\mathrm{Ib}(\mathrm{PSC}-\mathrm{Ib})$ are supercooled ternary $\left(\mathrm{H}_{2} \mathrm{SO}_{4}, \mathrm{HNO}_{3}, \mathrm{H}_{2} \mathrm{O}\right)$ solution (STS, liquid particles) clouds, and type II (PSC-II) are water ice clouds $\left(T_{\text {ice }}=185 \mathrm{~K}\right.$ at $\left.30 \mathrm{hPa}\right)$.

Arctic temperatures are close to the threshold of PSC formation, hence both spatial and temporal PSC distributions present a high variability at daily and yearly scales. In contrast, PSC presence in the Antarctica is almost ubiquitous from the beginning of wintertime to early springtime, since Antarctic temperatures can reach rather lower values than those present in the Arctic (Parrondo et al., 2007), leading to higher occurrence of PSCs over the Antarctic Continent.

Lidar measurements have been widely used for PSC classification on the basis of two lidar variables: the backscattering ratio (total backscatter-to-molecular coefficient ratio, $R$ ) and the volume linear depolarization ratio $\left(\delta^{\mathrm{V}}\right)$. Indeed, due to the fact that nonspherical particles change the polarization state of the incident light, unlike spherical particles, both PSC-I (subtype Ia corresponding to solid particle NAT clouds and subtype Ib to liquid STS clouds) and PSC-II (ice clouds), as well as their mixtures, can be detected and identified by using lidar systems with depolarization measurement capabilities. Larger $R$ and $\delta^{\mathrm{V}}$ values are found when PSC-IIs occur, whereas PSC-Ia and -Ib, and their mixtures, present smaller $R$ and $\delta^{\mathrm{V}}$ values (e.g., Adriani et al., 2004; Maturilli et al., 2005; Pitts et al., 2009). PSC-Is and PSC-IIs have been detected in both hemispheres; however, the presence of ice clouds over the Southern Hemisphere is more frequent due to the fact that Antarctic temperatures usually can reach rather lower values than those in the Arctic, as result of a stronger and more stable Antarctic vortex during wintertime (Waugh and Polvani, 2010). However, although ice clouds can provide aerosol surface areas 100 times greater than those of liquid STS (PSC-Ib) or NAT (PSC-Ia) clouds for chlorine activation (e.g., Carslaw et al., 1998; Lowe and MacKenzie, 2008), thus favouring an enhancement of the ozone reduction as compared to that PSC-I clouds would present, their occurrence is rather lower than that for PSC-I (e.g., Adriani et al., 2004; Maturilli et al., 2005; Pitts et al., 2009). Therefore a more relevant role on ozone depletion is actually linked to liquid STS and NAT PSCs, which are the most important PSCs for chlorine activation and denitrification processes, respectively, involved in ozone destruction. Indeed, long-term PSC field monitoring together with PSC-type identification are critical in polar ozone depletion research, and hence directly linked to stratospheric temperature variability.

The Instituto Nacional de Técnica Aeroespacial (INTA, Spain) in collaboration with the Dirección Nacional del Antártico/Instituto Antártico Argentino (DNA/IAA, Argentina) have been performing an extensive program for stratospheric ozone monitoring and research in Antarctica. One of the objectives was the climatology of high clouds in coastal Antarctica to link two highly correlated fields: PSC formation and ozone depletion (Solomon, 1999). In the frame of the International Polar Year (IPY), an improved version of the standard NASA/Micro Pulse Lidar (MPL-4, Sigma Space Corp.), which includes a built-in depolarization measurement module, is currently used for PSC observations in the Antarctic Belgrano II station (Argentina, $77.9^{\circ} \mathrm{S}$ $34.6^{\circ} \mathrm{W}, 256 \mathrm{~m}$ a.s.1.) since 2009 . The column of air above this station remains well inside the polar vortex during wintertime (Parrondo et al., 2007), as shown in Fig. 1 in relation to the Antarctic polar vortex on 24 June 2010 as an example, providing thus an excellent location for PSC observations. Older versions than the MPL-4 have already been deployed in two other Antarctic stations (see Fig. 1): Syowa (Japan, $69.0^{\circ} \mathrm{S} 39.5^{\circ} \mathrm{E}$ ), where a PSC type-II single event was reported and attributed to low temperature fluctuations related to inertia gravity waves (Shibata et al., 2003) and remaining usually outside the polar vortex (see Fig. 1); and South Pole/Amundsen-Scott (USA, 89.98 ${ }^{\circ} \mathrm{S} 24.8^{\circ} \mathrm{E}$ ) on the Antarctic Plateau ( $2835 \mathrm{~m}$ a.s.1.), where a 5 -yr data record was obtained by using the noisier MPL-3 (Micro Pulse Lidar 


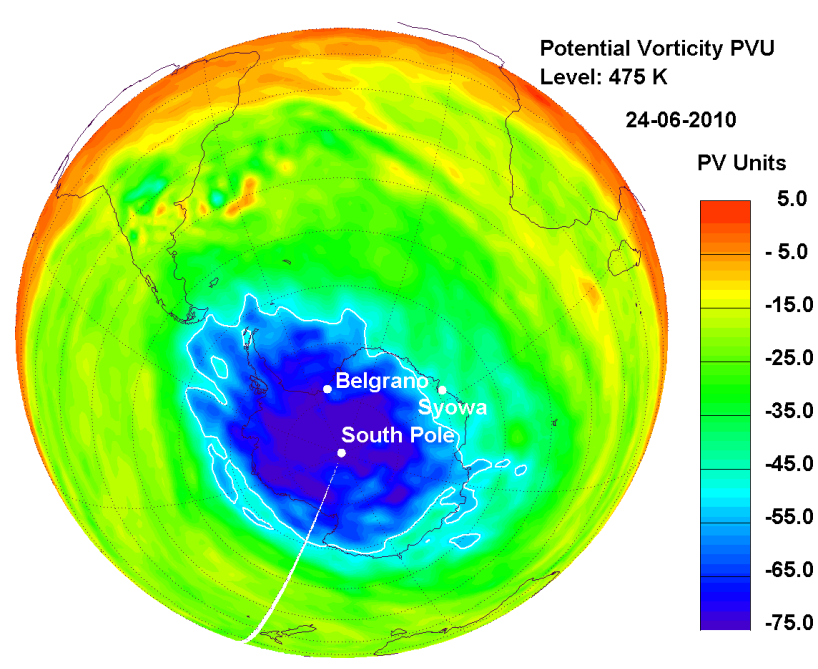

Fig. 1. Stable polar vortex over Antarctica represented by the potential vorticity (PV) at $475 \mathrm{~K}$-level on 24 June 2010 . The white line indicates the edge of the polar vortex. Also shown are the location of Belgrano II station (Argentina, $77.9^{\circ} \mathrm{S} 34.6^{\circ} \mathrm{W}$ ) together with Syowa (Japan, $69.0^{\circ} \mathrm{S} 39.5^{\circ} \mathrm{E}$ ), which is outside the polar vortex edge, and South Pole/Amundsen-Scott (USA, $89.98^{\circ}$ S $24.8^{\circ} \mathrm{E}$ ) stations.

version 3) with careful smoothing procedures (Campbell and Sassen, 2008). However, none of them includes polarization measuring capabilities similar to those of the MPL-4.

A good performance of the MPL-4 system for PSC detection was previously achieved in the Arctic (CórdobaJabonero et al., 2009), where depolarization data confirmed that all the PSC cases detected during the 2006-2007 winter were related only to PSC-I events, and no PSC-II occurrences with larger $\delta^{\mathrm{V}}$ values were found. In particular, the MPL-4 performance for discriminating Type I (Ia and Ib) and Type II PSCs in relation with the $\delta^{\mathrm{V}}$ parameter is still to be evaluated. This evaluation is focused on: (1) a more detailed estimation of $\delta^{\mathrm{V}}$ from MPL-4 measurements, based on the analysis of the two-channel data, i.e., both parallel (p-) and perpendicular (s-) polarization MPL signals, and (2) the intercomparison with a reliable lidar located not far from the Belgrano II station.

The space-borne lidar CALIOP (Cloud-Aerosol Lidar with Orthogonal Polarization) on board the CALIPSO (Cloud-Aerosol Lidar and Infrared Pathfinder Satellite Observation, http://www-calipso.larc.nasa.gov) has provided valuable PSC information since 2006 at regional scales over both poles (Pitts et al., 2007, 2009, 2011). Therefore, MPL-4 depolarization retrievals of Antarctic PSCs are analyzed in comparison with the PSC volume linear depolarization ratio $\delta^{\mathrm{V}}$ reported from the space-borne lidar CALIOP to test the degree of agreement between both data sets.

Both of the lidar systems and the depolarization data processing are described in Sect. 2. Section 3 presents results and discussion together with the analysis procedures applied to both $\delta^{\mathrm{V}}$ data sets, where three different approaches are considered for that comparison analysis. Finally, the main conclusions are summarized in Sect. 4.

\section{Instrumentation and methods}

\subsection{Lidar systems}

\subsubsection{Ground-based lidar: MPL-4}

The Micro Pulse Lidar version 4 (MPL-4, Sigma Space Corp.) is an improved version of the standard Micro Pulse Lidar version 3 (MPL-3, SES Inc.) in routine operation within the NASA/MPLNET (Micro-Pulse Lidar Network, http:// mplnet.gsfc.nasa.gov) (Campbell et al., 2002). The MPL4 system is small, easy-to-handle with high autonomy and operational in full-time continuous mode. MPL-4 is configured in a zenith, monostatic, coaxial alignment and is based on an eye-safe pulsed Nd: YLF (neodymium-doped yttrium lithium fluoride) laser emitting at $527 \mathrm{~nm}$ with a high repetition rate $(2500 \mathrm{~Hz})$ and low energy $(10 \mu \mathrm{J}$, max.). Its receiver system consists of a Maksutov-Cassegrain 18-cm diameter telescope, a birefringent polarizer cell, and an avalanche photodiode detector. Backscattered signals are registered with a 1-min integration time and 75-m vertical resolution, commuting at each time the polarization module from parallel- to perpendicular-polarized detection ( $\mathrm{p}$ - and s-channels, respectively). These 1-min signals registered in alternative mode for each p- and s-channel are hourly averaged, providing 30-min averaged p- and s-signal profiles in one hour. These hourly averaged profiles are usually analyzed to study the spatial and temporal variability of the PSC distribution. This MPL-4 configuration allows for probing the atmosphere up to $30 \mathrm{~km}$ with a sufficient signal-to-noise ratio (SNR). A full overlap is achieved at altitudes around $4 \mathrm{~km}$ up; however, the impact of the incomplete overlap effect on our retrievals is irrelevant because of: (1) its cancellation in the definition of $\delta^{\mathrm{V}}$ (see Eq. 1 in Sect. 2.2), and (2) PSCs frequently appear at higher altitudes where a full overlap is achieved.

\subsubsection{Space-borne lidar: CALIOP}

The CALIPSO satellite carries the space-borne lidar instrument CALIOP, which provides horizontally (along the CALIPSO ground-track) and vertically resolved measurements for aerosol and clouds distributions at a global scale. CALIOP is based on a diode-pumped Nd:YAG (neodymium-doped yttrium aluminum garnet) laser emitting linearly polarized pulses with a repetition rate of $20.16 \mathrm{~Hz}$ and a pulse length of $\sim 20 \mathrm{~ns}$, energy per pulse of $220 \mathrm{~mJ}$ at $1064 \mathrm{~nm}$ and $\sim 110 \mathrm{~mJ}$ at $532 \mathrm{~nm}$. Its receiver system consists of a 1-m diameter, telescope which feeds a threechannel receiver measuring the backscattered intensity at $1064 \mathrm{~nm}$ and the two orthogonal polarization components at $532 \mathrm{~nm}$, parallel (p) and perpendicular (s). A full description 
of the CALIOP system can be found in Winker et al. (2007) and Hunt et al. (2009). CALIOP provides data at $532 \mathrm{~nm}$ (the closest wavelength to that of the MPL-4 system) with a different vertical resolution as a function of altitude: $30 \mathrm{~m}$ at heights lower than $8.2 \mathrm{~km}, 60 \mathrm{~m}$ at $8.2-20.2 \mathrm{~km}, 180 \mathrm{~m}$ at $20.2-30.1 \mathrm{~km}$, and $300 \mathrm{~m}$ at $30.1-40.0 \mathrm{~km}$. In order to improve the SNR, a horizontal averaging over 5-km CALIPSO ground-track and a vertical 7-point adjacent averaging are applied. The latter data smoothing is achieved by using a sliding window of 7 points for averaging through the entire profile. As a result, the final vertical resolution of the CALIOP data remains unchanged.

\subsection{Depolarization data processing}

The first lidar measurements of polarization properties were performed in the early 1970s (Schotland et al., 1971; Pal and Carswell, 1973). It is well known that spherical particles do not change the polarization state of the incident light, while a partial depolarization component is introduced in the $180^{\circ}$ backscattered signal after interacting with nonspherical particles. Several definitions are available in the lidar community to describe the depolarization phenomena caused by atmospheric constituents. A review of the most common parameters used in the lidar literature is given by Cairo et al. (1999). In our study, one of the most basic definitions is used, i.e., the volume linear depolarization ratio $\delta^{\mathrm{V}}$ defined as follows

$\delta^{\mathrm{V}}(z)=\frac{\beta^{\perp}(z)}{\beta^{\|}(z)}$,

where $\beta^{\perp}(z)$ and $\beta^{\|}(z)$ are the backscatter (particles plus molecules) coefficients for perpendicular- and parallelpolarization planes, respectively, and $z$ is the height. In general, the term "particles" refers to both cloud and aerosol particles.

\subsubsection{Ground-based depolarization measurements}

From the practical point of view, the most general expression to calculate the volume linear depolarization ratio $\delta^{\mathrm{V}}$ is

$\delta^{\mathrm{V}}(z)=K \frac{P^{\perp}(z)}{P^{\|}(z)}+\chi$,

where $P^{\perp}(z)$ and $P^{\|}(z)$ are the s- and p-components of the measured MPL signals, respectively, once corrected for intrinsic instrumental factors (Campbell et al., 2002); $K$ is a calibration constant that accounts for the differences of the receiver channel gains; and $\chi$ is a correction to account for any slight mismatch in the transmitter and detector polarization planes and any impurity of the laser polarization state (Sassen and Benson, 2001; Sassen, 2005). Because only a single detector is used in the MPL-4, the gain ratio is unity by definition and calibration requirements are vanished, however, at the expense of nonsimultaneous measurements
Table 1. Mean $\chi$ values together with their SD (\%SD) and the number of profiles used.

\begin{tabular}{lrrr}
\hline Year & $\chi$ & SD (\%SD) & $\begin{array}{r}\text { Number of } \\
\text { profiles }\end{array}$ \\
\hline 2009 & -0.053 & $0.005(10.4)$ & 271 \\
2010 & -0.059 & $0.006(10.8)$ & 275 \\
2011 & -0.053 & $0.008(15.4)$ & 232 \\
\hline Mean/Total & -0.055 & $0.003(5.2)$ & 778 \\
\hline
\end{tabular}

of the polarization components (see the review of existing techniques for estimating gain ratio in Álvarez et al., 2006). Fortunately, the impact of non-simultaneity on our retrievals is negligible due to the rather small PSC variability during the integration time (1 min) of each measurement. Thus, $K$ is considered to be 1 . The remaining correction term $\chi$ can be estimated by probing the $\delta^{V}$ values at middle and upper troposphere altitudes under both aerosol- and cloudfree conditions (calibration window). Optimal $\chi$ values are obtained by using fitting procedures with molecular backgrounds, considering a molecular volume linear depolarization ratio $\delta_{\mathrm{mol}}=0.0144$. Mean values of $\chi$ found for each year are presented in Table 1, showing a data dispersion of $5 \%$ among these three years (a total of 778 hourly averaged profiles were selected for that purpose). Those $\chi$ values are then used for calibration of the MPL-4 depolarization measurements following Eq. (2).

Regarding time averaging procedures applied to the MPL4 measurements, hourly averaged MPL- $4 \delta^{\mathrm{V}}$ profiles, as obtained from those 30-min averaged p- $\left(P^{\|}(z)\right)$ and s-signal $\left(P^{\perp}(z)\right)$ profiles in one hour (see Sect. 2.1.1 for details), are those used in the comparison with CALIOP data instead of instantaneous 1-min profiles $\left(\delta_{1-\min }^{V}\right)$. As aforementioned (see Sect. 2.1.1), this improves the SNR of the lidar measurements at Belgrano II station. Indeed, the level of noise decreases as the time averaging increases, as shown in Fig. 2 (for instance, data on 1 July 2009). $\delta^{\mathrm{V}}$ variations depending on the time averaging (5-, 10-, 15- and 30-min averaged profiles are shown in Fig. 2) reveal that the vertical $\delta^{\mathrm{V}}$ structure presents a clearly enhanced SNR when the time averaging is higher than $15 \mathrm{~min}$. In particular, an additional PSC feature at around $25 \mathrm{~km}$ height can be identified with enough SNR only for 15-min and 30-min averaging of the MPL-4 data (see Fig. 2).

Moreover, MPL- $4 \delta^{\mathrm{V}}$ fluctuations along that hour are also studied by examining the differences between instantaneous 1 -min $\left(\delta_{1-\min }^{V}\right)$ and hourly averaged $\left(\delta^{\mathrm{V}}\right)$ profiles within the same hour. Mean differences and their RMS values are shown in Fig. 3 (for instance, data on 1 July 2009). A heightaveraged value of $-0.005 \pm 0.013$ is obtained for these mean differences, and their RMS values show that temporal $\delta^{\mathrm{V}}$ fluctuations are lower than $0.05,0.1$ and 0.25 up to altitudes of $18 \mathrm{~km}, 23 \mathrm{~km}$ and $30 \mathrm{~km}$ height, respectively. 


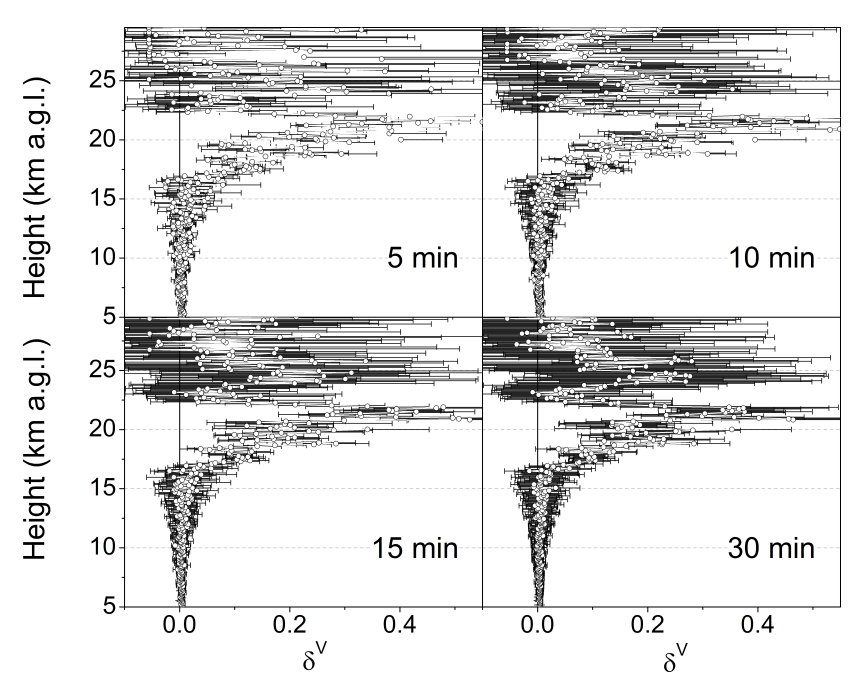

Fig. 2. MPL-4 $\delta \mathrm{V}$ profiles (white-lined open circles, in black background of their SD values) on 1 July 2009 depending on the time averaging (see legend inside each panel, from up to down and right to left): 5-, 10-, 15- and 30-min averaged profiles.

In summary, a high SNR is achieved for a time averaging of $30 \mathrm{~min}$ applied to MPL-4 p- and s-signal profiles (i.e., hourly averaged $\delta^{\mathrm{V}}$ profiles) in our comparison analysis, and temporal $\delta^{\mathrm{V}}$ fluctuations per hour are lower than 0.1 up to altitudes where PSC features more frequently appear.

An example of this calibration procedure performed on 1 July 2009 is illustrated in Fig. 4, where the volume linear depolarization ratio $\delta^{\mathrm{V}}$ (left panel) together with the backscattering ratio $R$ (centre panel) and the closest temperature profile provided from the local radiosounding (29 June 2009 at 11:00 UTC, right panel) are also represented. $R$, the total backscatter-to-molecular coefficient ratio (or the normalised $R, R_{\text {norm }}=1-\frac{1}{R}$ ) usually used for PSC detection, is obtained by using a lidar ratio (extinction-tobackscatter coefficient ratio) of $30 \mathrm{sr}$ in the Klett-Fernald inversion algorithm for backscatter coefficient retrieval (Klett, 1981; Fernald, 1984). A reference height is fixed when the condition of $R=1$ ( $R_{\text {norm }}=0$, the strict case for an aerosoland cloud-free molecular atmosphere) is found in the calibration window range considered. On this particular day, a mean value of $\chi=-0.055 \pm 0.009$ is computed from the 24 daily profiles by using a calibration window from 5 to $7 \mathrm{~km}$ a.g.l. (gray band in Fig. 4). This value is similar to that reported for 2009 (see Table 1), which was applied to the 2009 winter data set.

A similar procedure is applied to all other uncalibrated MPL-4 $\delta^{\mathrm{V}}$ profiles. In particular, PSC depolarization features observed on 1 July 2009, once the $\delta^{\mathrm{V}}$ profile is calibrated, present $\delta^{\mathrm{V}}$ values larger than 0.2 at altitudes from 18.5 to $22 \mathrm{~km}$ and from $24 \mathrm{~km}$ height upwards, where a maximum $\delta^{\mathrm{V}}=0.5$ at $21-22 \mathrm{~km}$ height is identified (see Fig. 4, left), and $R \cong 10\left(R_{\text {norm }} \cong 0.9\right)$ is found (see Fig. 4 , centre). This

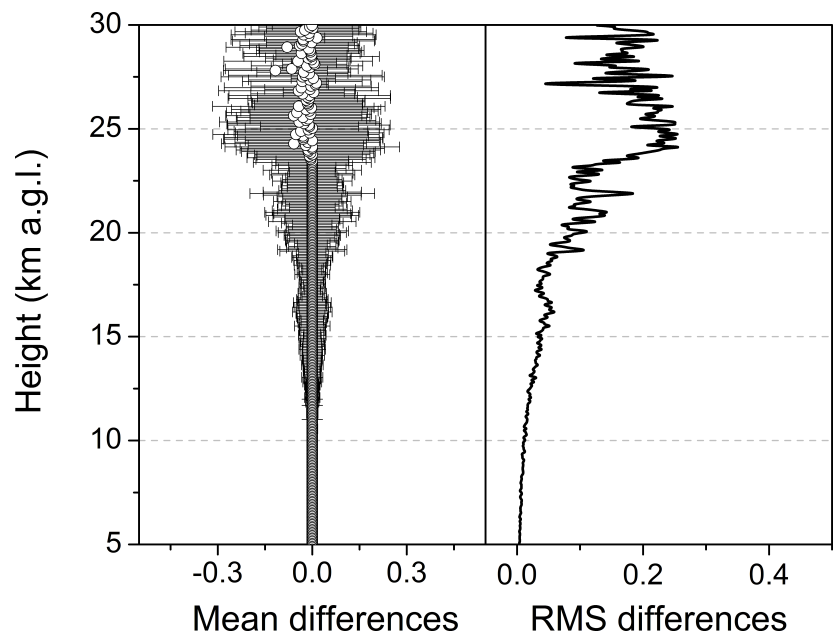

Fig. 3. MPL-4 mean $\left(\delta_{1-\min }^{\mathrm{V}}-\delta^{\mathrm{V}}\right)$ differences along an hour and their RMS values (for instance, data on 1 July 2009).

combination of $R$ and $\delta^{\mathrm{V}}$ values is typical for PSC-II events, as reported for several studies (e.g., Adriani et al., 2004; Maturilli et al., 2005; Pitts et al., 2009). This PSC-II feature is also confirmed by radiosonde data (see Fig. 4, right), reporting temperatures at those altitudes between 19.5 and $26.5 \mathrm{~km}$ height lower than the threshold for PSC-II formation, i.e., where $T<T^{\text {PSC-II }}$ (see Fig. 4, right, gray-shaded bands). These threshold temperatures for PSC-I ( $T^{\text {PSC-I }}$, thin dashed line in Fig. 4) formation have been calculated according to the parameterizations of Hanson and Mauersberger (1988) assuming 5-ppmv $\mathrm{H}_{2} \mathrm{O}$ and 10-ppbv $\mathrm{HNO}_{3}$; and for PSC-II ( $T^{\text {PSC-II }}$, thin solid line in Fig. 4) they were estimated from Marti and Mauersberger (1993) with the same $\mathrm{H}_{2} \mathrm{O}$ amount. These proportions were obtained from Maturilli et al. (2005), where these values were reported as typical for this month.

However, $T^{\text {PSC-I }}$ and $T^{\text {PSC-II }}$ can vary depending on the real amounts of $\mathrm{HNO}_{3}$ and $\mathrm{H}_{2} \mathrm{O}$. Therefore, additionally, as the local radiosounding water vapor profile is available, the same calculations have been performed by using the in situ $\mathrm{H}_{2} \mathrm{O}$ concentration (radiosonde data) instead of a constant value. These new threshold temperatures for PSC-I and PSCII formation are also shown in Fig. 4 (thick dashed and solid lines, respectively), and differences are clearly found with respect to those previously obtained. In particular, no PSC-II region $\left(T<T^{\text {PSC-II }}\right)$ would be observed, differing the lidar results found as indicated by both the $R$ and $\delta^{\mathrm{V}}$ parameters. These discrepancies can be likely due to the nonsimultaneous lidar measurements with local available radiosounding data, at least for this day. Hence, a further study must be addressed on the relation between the PSC-type features and the stratospheric temperature variability, regarding the temperature thresholds for PSC formation. Nevertheless, this is out of the scope of this work. 


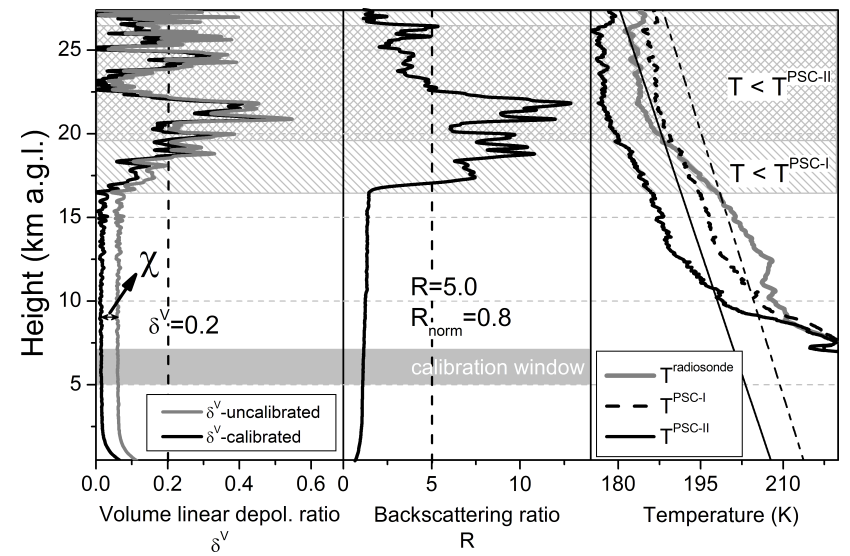

Fig. 4. An example of calibration of the volume linear depolarization ratio $\delta^{\mathrm{V}}$. From left to right: $1 \mathrm{~h}$-averaged (01:00-02:00 UTC) $\delta^{\mathrm{V}}$ profile on 1 July 2009, once calibrated (black line) and before calibration (gray line); the corresponding backscattering ratio $R$ profile; and the closest available temperature radiosounding on 29 June 2009 at 11:00 UTC (gray line). The threshold temperatures for PSC-I ( $\left.T^{\text {PSC-I }}\right)$ and PSC-II $\left(T^{\text {PSC-II }}\right)$ formation are also shown assuming: 10-ppbv $\mathrm{HNO}_{3}$ and 5-ppmv $\mathrm{H}_{2} \mathrm{O}$ (thin dashed and solid lines, respectively) as typical values for June (Maturilli et al., 2005), and the in situ water vapor concentration profile (radiosonde data) (thick dashed and solid lines, respectively). Calculations have been performed using the parameterizations of Hanson and Mauersberger (1988) for PSC-I, and Marti and Mauersberger (1993) for PSC-II. CALIPSO ground-track distance was $3.6 \mathrm{~km}$ from the Belgrano II station on this day.

\subsubsection{Space-borne depolarization measurements}

CALIPSO provides Level 1, Level 2 and Level 3 products. Level 1 products include lidar calibrated and geo-located profiles of attenuated-backscatter coefficient at $1064 \mathrm{~nm}$, and total and perpendicular-polarized attenuated backscatter coefficient at $532 \mathrm{~nm}$. Level 2 products include cloud layer, aerosol layer and aerosol profiles at different horizontal resolutions. Level 3 products are monthly averaged profiles of aerosol optical properties on a uniform grid in the tropospheric region for altitudes below $12 \mathrm{~km}$ height. A detailed description of products Levels 1 and 2 can be seen in Powell et al. (2010). The Level 1 V3-01 (version 3.01, validated stage 1) attenuated-backscatter profile products at $532 \mathrm{~nm}$ (total and perpendicular-polarized) are used in this study. The attenuated-backscatter coefficient profile is defined as the volume backscatter coefficient $\beta$ multiplied by the twoway atmospheric transmission $T^{2}$ (Hostetler et al., 2006). The total linear depolarization ratio $\delta_{\text {total }}$ is defined as

$\delta_{\text {total }}(z)=\frac{\beta^{\perp}(z)}{\beta^{\text {total }}(z)}$,

where $\beta^{\text {total }}=\beta^{\perp}+\beta^{\|}, \beta^{\perp}(z)$ and $\beta^{\|}(z)$ are the backscatter (particles and molecules) coefficients for s- and p-polarized components, respectively, and $z$ is the range. Again, the term "particles" refers to both cloud and aerosol particles. For convenience, Eq. (3) can be multiplied by the term $T^{2}$, allowing for expressing the total linear depolarization ratio $\delta_{\text {total }}$ in terms of attenuated-backscatter coefficients:

$\delta_{\text {total }}(z)=\frac{\beta^{\perp}(z)}{\beta^{\text {total }}(z)}=\frac{\beta^{\perp}(z) \cdot T^{2}}{\beta^{\text {total }}(z) \cdot T^{2}}=\frac{\beta_{\mathrm{att}}^{\perp}(z)}{\beta_{\mathrm{att}}^{\text {total }}(z)}$,

where $\beta_{\text {att }}^{\text {total }}=\beta_{\text {att }}^{\perp}+\beta_{\text {att }}^{\|}$, and $\beta_{\text {att }}^{\perp}(z)$ and $\beta_{\text {att }}^{\|}(z)$ are the attenuated-backscatter coefficient for s- and p-polarized components, respectively. $\beta_{\text {att }}^{\perp}$ and $\beta_{\text {att }}^{\text {total }}$ are provided by the CALIPSO Level 1 products. Finally, the $\delta_{\text {total }}$ values are converted into $\delta^{\mathrm{V}}$ values using the following relationship (Cairo et al., 1999)

$\delta^{\mathrm{V}}(z)=\frac{\delta_{\text {total }}(z)}{1-\delta_{\text {total }}(z)}$.

Therefore, the volume linear depolarization ratio $\delta^{\mathrm{V}}$ can be compared between both MPL-4 and CALIOP data sets.

However, despite smoothing and averaging procedures applied (see Sect. 2.1.2), high negative $\delta^{\mathrm{V}}$ values inside the CALIOP data set were observed, mainly at higher altitudes. Therefore, in order to avoid the data contamination with such "unrealistic" values, an a priori filtering of data is proposed. Restriction conditions to those $\delta^{\mathrm{V}}$ values are based on the CALIPSO observations reported by Pitts et al. (2009), where most of aerosol depolarization ratio $\left(\delta_{\mathrm{a}}\right)$ data were shown between -0.1 and 0.8 , about $14 \%$ of overall CALIOP data falling outside these limits. Note that volume linear depolarization ratio $\delta^{\mathrm{V}}$ data are presented here instead of those $\delta_{\mathrm{a}}$ data. Therefore, the corresponding restriction limits are calculated for $\delta^{\mathrm{V}}$ by using the formulation reported by Cairo et al. (1999), linking both these magnitudes. Hence, $\delta^{\mathrm{V}}$ can be expressed as a function of the molecular depolarization ratio $\delta_{\text {mol }}$, the backscattering ratio $R$ and $\delta_{\mathrm{a}}$, as follows

$\delta^{\mathrm{V}}=\frac{\delta_{a} \times\left(R \times \delta_{\mathrm{mol}}+R-1\right)+\delta_{\mathrm{mol}}}{\delta_{\mathrm{a}}+(R-1) \times \delta_{\mathrm{mol}}+R}$,

where $R$ values are varied between 1 and $30, \delta_{\mathrm{a}}$ between -0.1 and 0.8 (Pitts et al., 2009), and $\delta_{\text {mol }}$ takes these two values: 0.00366 (Cabannes scattering) and 0.0144 (total Rayleigh). Among all the possible combinations, the minimal (-0.1) and maximal (0.8) values are computed. Hence, these limits will act as a conservative restriction range for the overall of $\delta^{\mathrm{V}}$ values in both lidar data sets, which are the same presented for $\delta_{\mathrm{a}}$ in Pitts et al. (2009). In fact, about $14 \pm 11 \%$ and $5 \pm 3 \%$ of overall CALIOP and MPL- 4 data, respectively, falling outside of these limits, have been disregarded for the comparison analysis performed between both lidar data sets. 


\section{Results and discussion}

\subsection{Lidar data sets}

PSC observations have been performed at the Belgrano II station since 2009 to the present. MPL-4 measurements for the 2009-2011 Antarctic winters, from May to September, are used for this study. Lidar data sets are compared under the following conditions: coincident profiles in time, with simultaneous measurements carried out at timescales lower than two hours around the CALIPSO overpass, and in space, with CALIPSO ground-track separations from the station closer than $55 \mathrm{~km}$ distance. During those winter times, a total of 189 CALIPSO overpasses near the Belgrano II station were carried out within less than a $55 \mathrm{~km}$ distance. Among them, 104 overpasses are coincident events with MPL-4 measurements reporting PSC detection and 48 of them are simultaneously available for comparison. Moreover, 35 more lidar profiles are analyzed in order to examine the influence on spatial scales when data from rather large CALIPSO overpass distances are included in that lidar comparison. Those additional 35 profiles correspond to separations between 70 and $100 \mathrm{~km}$. In general, four predominant distance ranges are observed: 0-10 km, 20-30 km, 45-55 km and 70-90 km. All these PSC cases, listed by the CALIPSO ground-track distance from the Belgrano II station, are shown in Table 2.

A height interval from 5 to $30 \mathrm{~km}$ is selected for the comparison between lidar profiles. A delineating altitude of $10 \mathrm{~km}$ has been conservatively established as the lower limit for the unambiguous presence of PSCs, distinguishing them from other upper tropospheric clouds (mainly cirrus clouds). The lower limit of $10 \mathrm{~km}$, chosen in this work for PSC detection, is based on the fact that the tropopause is not clearly delineated by the temperature profile during wintertime in deep Antarctica (Rubin, 1953). Indeed, a traditional tropopause height, denoted by rapidly increasing static stability above it, can be approximated from December through March in Belgrano II station sounding data at around $9 \mathrm{~km}$. During winter months, however, temperatures decrease with height to nearly $23 \mathrm{~km}$. Dynamic coupling between the troposphere and stratosphere is more likely in such conditions. The region from 8 to $10 \mathrm{~km}$ is considered a transitional zone, where cloud type cannot be established with any certainty. Although our study is restricted to PSC formation altitudes, the $5-10 \mathrm{~km}$ height interval is also considered for contrast as a PSC-free region. Heights above $30 \mathrm{~km}$ are disregarded due to a decreasing of the MPL-4 SNR. Finally, along the overall height interval selected, every $0.5-\mathrm{km}$ layer is averaged for comparing the MPL-4 and CALIOP data sets. Note that negative $\delta^{\mathrm{V}}$ values are not disregarded during the smoothing process of CALIOP data profiles (see Sects. 2.1 and 2.2). Only $\delta^{\mathrm{V}}$ values falling outside the $(-0.1,0.8)$ interval are ignored when this $0.5-\mathrm{km}$ vertical averaging is applied to both lidar profiles.

\subsection{Comparison analysis}

Three different approaches are considered for the comparison between both lidar $\delta^{\mathrm{V}}$ data sets in order to test the degree of agreement as a function of the CALIPSO ground-track separation from Belgrano II station:

1. the correlation coefficient (CC), as a measure of the relationship between both PSC vertical layering structures;

2. the mean differences, $\Delta(z)=\delta^{\mathrm{MPL}}(z)-\delta^{\mathrm{CAL}}(z)$, between both MPL- 4 and CALIOP $\delta^{\mathrm{V}}$ profiles, together with their root mean square (RMS) values; and

3. the percentage difference, BIAS $(z)$, since this parameter is also used in profiling comparisons between CALIOP and other ground-based lidar systems (Mamouri et al., 2009; Mona et al., 2009), and defined as

$\operatorname{BIAS}(z)=\frac{100 \times\left[\delta^{\mathrm{MPL}}(z)-\delta^{\mathrm{CAL}}(z)\right]}{\delta^{\mathrm{CAL}}(z)}$.

For all these three approaches, $\delta^{\mathrm{MPL}}(z)$ and $\delta^{\mathrm{CAL}}(z)$ are the $0.5-\mathrm{km}$ averaged volume linear depolarization ratio $\delta^{\mathrm{V}}$ profiles for MPL-4 and CALIOP, respectively.

\subsubsection{Comparison analysis I: linear regression and correlation coefficient $(\mathrm{CC})$}

The correlation coefficient (CC) between the $0.5-\mathrm{km}$ averaged MPL-4 and CALIOP profiles was calculated for 83 cases over the total altitude range (see Table 2). Among these cases, 12, 24, 12 and 35 of them, respectively, correspond to the four predominant CALIPSO distance ranges: $<10 \mathrm{~km}$, 20-30 km, 45-55 km and 70-90 km, denoted as D1, D2, D3 and D4, respectively. This analysis is also performed as a function of different altitude intervals in order to examine similarities and/or discrepancies between different PSC layers as observed by both MPL-4 and CALIOP in each case. This procedure can reveal the degree of agreement between both vertical layering structures as the height increases. Five height intervals for correlation fitting are selected: $5-10 \mathrm{~km}$, $5-15 \mathrm{~km}, 5-20 \mathrm{~km}, 5-25 \mathrm{~km}$ and 5-30 km. Table 2 summarizes the results. They are based on the significance of these correlation coefficients obtained. Therefore, a value of $\mathrm{CC}=0.5$ is considered statistically significant depending on the number of data points deemed into the calculation, where a p-value less than the chosen significance level $\alpha$ of 0.05 must be reported. In particular, for the case of a height interval of 5-15 km with a smaller number of data points than that for other height intervals considered in this study, a test statistic $t=2.09$ and $\mathrm{CC}=0.46$ are obtained reporting $\mathrm{p}$-values lower than 0.05 . Consequently, for other height intervals with larger number of data points, $p$-values must be also lower than $\alpha$, and therefore those obtained CC can be regarded as statistically significant in this study. 
Table 2. Coincident PSC events between MPL-4 and CALIOP measurements at four predominant CALIPSO ground-track distance ranges from Belgrano II station: Correlation coefficient (CC) for three selected height intervals, and the calculated height-averaged BIAS, BIAS ${ }_{z}$, and their SD together with the number of data points ( $N^{\mathrm{BIAS}}$ in $\%$, with respect to the total data points) fulfilling the constraint condition $(-50 \%<\mathrm{BIAS}<+50 \%)$. Particularly analysed cases are marked by asterisks.

\begin{tabular}{|c|c|c|c|c|c|c|c|}
\hline $\begin{array}{c}\text { Distance } \\
(\mathrm{km})\end{array}$ & Date & $\begin{array}{c}\mathrm{CC} \\
5-20 \mathrm{~km}\end{array}$ & $\begin{array}{c}\mathrm{CC} \\
5-25 \mathrm{~km}\end{array}$ & $\begin{array}{c}\mathrm{CC} \\
5-30 \mathrm{~km}\end{array}$ & $\begin{array}{c}\mathrm{BIAS}_{z} \\
(\%)\end{array}$ & $\mathrm{SD}(\%)$ & $\begin{array}{c}N^{\mathrm{BIAS}} \\
(\%)\end{array}$ \\
\hline \multicolumn{8}{|c|}{ Distance range (D1): $<10 \mathrm{~km}(12$ cases $)$} \\
\hline 3.28 & $15 / 06 / 2009$ & 0.34 & 0.19 & 0.06 & -10 & 23 & 12 \\
\hline$* 3.55$ & 01/07/2009 & 0.85 & 0.91 & 0.54 & +2 & 31 & 38 \\
\hline 4.72 & 02/08/2009 & 0.77 & 0.66 & 0.52 & -8 & 27 & 22 \\
\hline$* 0.34$ & 25/09/2009 & 0.25 & 0.12 & 0.18 & -24 & 20 & 22 \\
\hline 1.58 & 08/06/2010 & 0.71 & 0.56 & 0.27 & -22 & 19 & 8 \\
\hline 1.98 & $24 / 06 / 2010$ & 0.89 & 0.83 & 0.78 & +3 & 23 & 44 \\
\hline 3.75 & 04/07/2010 & -0.23 & -0.21 & 0.00 & -11 & 30 & 10 \\
\hline 1.02 & $27 / 08 / 2010$ & 0.58 & 0.23 & 0.04 & +1 & 29 & 22 \\
\hline 3.05 & 07/07/2011 & 0.90 & 0.74 & 0.21 & -14 & 22 & 24 \\
\hline 2.48 & $29 / 07 / 2011$ & 0.70 & 0.57 & 0.32 & -16 & 26 & 36 \\
\hline 2.66 & $14 / 08 / 2011$ & 0.59 & 0.12 & -0.06 & -7 & 18 & 46 \\
\hline 2.73 & $24 / 08 / 2011$ & 0.70 & 0.61 & 0.62 & -11 & 26 & 22 \\
\hline \multicolumn{8}{|c|}{ Distance range (D2): $20-30 \mathrm{~km}$ (24 cases) } \\
\hline 26.9 & 28/06/2009 & 0.46 & 0.22 & -0.07 & 0 & 33 & 16 \\
\hline 25.5 & $30 / 06 / 2009$ & 0.73 & 0.95 & 0.51 & +5 & 25 & 28 \\
\hline 25.6 & $30 / 07 / 2009$ & 0.71 & 0.79 & 0.72 & -12 & 26 & 40 \\
\hline 27.0 & $01 / 08 / 2009$ & 0.51 & 0.34 & 0.35 & -21 & 30 & 26 \\
\hline 22.2 & $25 / 08 / 2009$ & 0.72 & 0.68 & 0.51 & -16 & 24 & 42 \\
\hline 30.1 & 27/08/2009 & 0.52 & 0.13 & 0.06 & -17 & 29 & 30 \\
\hline 23.3 & 26/09/2009 & 0.13 & -0.11 & 0.23 & -11 & 25 & 24 \\
\hline 29.0 & 28/09/2009 & 0.88 & 0.62 & 0.43 & -6 & 6 & 6 \\
\hline 22.4 & 09/06/2010 & 0.73 & 0.69 & 0.63 & -8 & 31 & 4 \\
\hline 29.8 & $11 / 06 / 2010$ & 0.51 & 0.44 & 0.41 & +5 & 26 & 24 \\
\hline 22.2 & $25 / 06 / 2010$ & 0.76 & 0.63 & 0.69 & -6 & 28 & 32 \\
\hline 29.9 & $27 / 06 / 2010$ & 0.49 & 0.48 & 0.48 & +4 & 29 & 34 \\
\hline 24.4 & 01/07/2010 & 0.39 & 0.39 & 0.18 & +9 & 30 & 12 \\
\hline$* 28.0$ & 03/07/2010 & 0.10 & 0.20 & 0.16 & +1 & 17 & 6 \\
\hline 29.0 & $13 / 07 / 2010$ & 0.54 & 0.00 & 0.28 & +5 & 27 & 40 \\
\hline 24.1 & $28 / 08 / 2010$ & 0.66 & 0.03 & 0.32 & -1 & 24 & 18 \\
\hline 23.5 & $19 / 09 / 2010$ & -0.03 & -0.16 & -0.19 & -6 & 34 & 10 \\
\hline 29.5 & $29 / 05 / 2011$ & 0.43 & -0.04 & 0.16 & -15 & 22 & 8 \\
\hline 29.3 & 06/07/2011 & 0.48 & 0.49 & 0.17 & -7 & 31 & 20 \\
\hline 28.9 & $16 / 07 / 2011$ & 0.65 & 0.50 & 0.34 & -8 & 26 & 30 \\
\hline 23.9 & $30 / 07 / 2011$ & 0.28 & 0.61 & 0.45 & -4 & 31 & 34 \\
\hline 23.9 & $15 / 08 / 2011$ & 0.20 & -0.18 & -0.24 & -9 & 29 & 20 \\
\hline 23.1 & $21 / 08 / 2011$ & 0.85 & 0.85 & 0.85 & -2 & 23 & 52 \\
\hline$* 29.4$ & 23/08/2011 & 0.76 & 0.75 & 0.53 & -12 & 23 & 60 \\
\hline \multicolumn{8}{|c|}{ Distance range (D3): 45-55 km (12 cases) } \\
\hline 50.1 & $29 / 06 / 2009$ & 0.05 & 0.81 & 0.55 & -2 & 32 & 18 \\
\hline 48.9 & $31 / 07 / 2009$ & 0.55 & 0.53 & 0.43 & -14 & 28 & 28 \\
\hline 54.0 & 27/09/2009 & 0.05 & -0.07 & -0.10 & -18 & 30 & 8 \\
\hline 55.5 & $10 / 06 / 2010$ & 0.06 & 0.12 & -0.10 & -18 & 26 & 8 \\
\hline 55.7 & $26 / 06 / 2010$ & 0.51 & 0.60 & 0.64 & +2 & 23 & 32 \\
\hline 49.7 & $02 / 07 / 2010$ & 0.53 & 0.60 & 0.62 & -14 & 23 & 32 \\
\hline$* 54.9$ & $12 / 07 / 2010$ & 0.25 & 0.31 & 0.15 & -5 & 31 & 42 \\
\hline 50.2 & $20 / 09 / 2010$ & 0.55 & 0.55 & 0.55 & -14 & 27 & 26 \\
\hline 56.8 & 28/05/2011 & -0.29 & -0.16 & 0.49 & -10 & 26 & 12 \\
\hline 50.3 & 03/06/2011 & -0.05 & -0.18 & -0.03 & +11 & 26 & 12 \\
\hline 56.7 & $15 / 07 / 2011$ & 0.54 & 0.41 & 0.19 & -10 & 24 & 30 \\
\hline$* 50.8$ & $22 / 08 / 2011$ & 0.84 & 0.60 & 0.60 & -17 & 22 & 42 \\
\hline
\end{tabular}


Table 2. Continued.

\begin{tabular}{|c|c|c|c|c|c|c|c|}
\hline $\begin{array}{l}\text { Distance } \\
(\mathrm{km})\end{array}$ & Date & $\begin{array}{c}\mathrm{CC} \\
5-20 \mathrm{~km}\end{array}$ & $\begin{array}{c}\mathrm{CC} \\
5-25 \mathrm{~km}\end{array}$ & $\begin{array}{c}C C \\
5-30 \mathrm{~km}\end{array}$ & $\begin{array}{c}\mathrm{BIAS}_{z} \\
(\%)\end{array}$ & $\mathrm{SD}(\%)$ & $\begin{array}{c}N^{\text {BIAS }} \\
(\%)\end{array}$ \\
\hline \multicolumn{8}{|c|}{ Distance range (D4): 70-90 km (35 cases) } \\
\hline 80.1 & $16 / 06 / 2009$ & 0.53 & 0.28 & 0.37 & -7 & 30 & 26 \\
\hline 78.8 & $26 / 06 / 2009$ & 0.61 & 0.03 & 0.65 & +5 & 24 & 20 \\
\hline 80.5 & 02/07/2009 & -0.07 & -0.17 & -0.06 & +1 & 35 & 6 \\
\hline 77.6 & 06/07/2009 & 0.17 & 0.56 & 0.48 & -8 & 27 & 18 \\
\hline 79.3 & $12 / 07 / 2009$ & -0.10 & 0.38 & 0.59 & -16 & 29 & 30 \\
\hline 81.2 & $18 / 07 / 2009$ & 0.07 & 0.65 & 0.38 & +7 & 24 & 22 \\
\hline 77.1 & $22 / 07 / 2009$ & -0.31 & -0.13 & -0.12 & -10 & 40 & 10 \\
\hline 75.6 & $28 / 07 / 2009$ & -0.16 & 0.49 & 0.13 & -23 & 16 & 8 \\
\hline 80.4 & $13 / 08 / 2009$ & 0.89 & 0.59 & 0.61 & +3 & 27 & 42 \\
\hline 82.4 & $19 / 08 / 2009$ & 0.19 & -0.10 & -0.10 & -5 & 28 & 28 \\
\hline 77.5 & 08/09/2009 & 0.65 & 0.56 & 0.50 & +3 & 25 & 20 \\
\hline 78.0 & $24 / 09 / 2009$ & 0.85 & 0.75 & 0.68 & -10 & 30 & 18 \\
\hline 82.8 & 05/07/2010 & 0.63 & 0.69 & 0.76 & +3 & 28 & 44 \\
\hline 77.7 & 09/07/2010 & 0.73 & 0.69 & 0.48 & -14 & 28 & 36 \\
\hline 78.5 & $25 / 07 / 2010$ & 0.68 & 0.24 & 0.10 & -16 & 30 & 12 \\
\hline$* 75.2$ & $31 / 07 / 2010$ & 0.87 & 0.86 & 0.56 & +4 & 25 & 46 \\
\hline 78.9 & $10 / 08 / 2010$ & -0.33 & -0.27 & -0.12 & -15 & 15 & 8 \\
\hline 75.2 & $16 / 08 / 2010$ & 0.71 & 0.47 & 0.26 & -17 & 23 & 28 \\
\hline 74.7 & 01/09/2010 & 0.51 & 0.33 & 0.17 & -42 & 5 & 8 \\
\hline 83.0 & 07/09/2010 & 0.20 & 0.03 & 0.04 & -6 & 30 & 26 \\
\hline 78.9 & $31 / 05 / 2011$ & 0.67 & 0.67 & 0.43 & +1 & 24 & 6 \\
\hline 73.0 & $31 / 05 / 2011$ & -0.07 & -0.46 & 0.35 & +1 & 32 & 18 \\
\hline 78.2 & $16 / 06 / 2011$ & 0.31 & 0.04 & -0.16 & +14 & 21 & 10 \\
\hline$* 83.9$ & $22 / 06 / 2011$ & 0.13 & 0.27 & 0.10 & -14 & 27 & 32 \\
\hline 78.3 & $26 / 06 / 2011$ & 0.48 & 0.42 & 0.12 & -11 & 20 & 34 \\
\hline 73.2 & 02/07/2011 & 0.42 & 0.77 & 0.55 & -13 & 21 & 28 \\
\hline 84.3 & 08/07/2011 & 0.74 & 0.57 & 0.32 & -17 & 26 & 60 \\
\hline 84.0 & $24 / 07 / 2011$ & 0.26 & 0.37 & 0.07 & -25 & 20 & 10 \\
\hline 73.4 & 03/08/2011 & 0.17 & 0.13 & 0.08 & -12 & 26 & 28 \\
\hline 78.7 & $13 / 08 / 2011$ & 0.35 & 0.04 & 0.04 & -18 & 25 & 32 \\
\hline 78.0 & $19 / 08 / 2011$ & 0.81 & 0.74 & 0.72 & +1 & 21 & 40 \\
\hline 73.0 & $19 / 08 / 2011$ & 0.32 & 0.31 & 0.10 & -4 & 29 & 18 \\
\hline 84.3 & $25 / 08 / 2011$ & -0.28 & -0.07 & -0.12 & -8 & 29 & 22 \\
\hline 79.0 & $29 / 08 / 2011$ & 0.64 & 0.26 & 0.06 & -19 & 32 & 18 \\
\hline 78.9 & $30 / 09 / 2011$ & 0.51 & 0.42 & 0.34 & -8 & 28 & 18 \\
\hline
\end{tabular}

A few dissimilarities can be observed between each year, but in general the correlation is better with a higher number of cases presenting $\mathrm{CC}$ values higher than 0.5 (referred as the frequency in \%) for the fitting height interval of 5-20 km, being slightly lower for those four others. In particular, among those 83 MPL-4/CALIOP profile coincidences examined in total during the 2009-2011 winter periods, 49 of them (59\%) present CC $>0.5$, at least in that fitting $5-20 \mathrm{~km}$ height interval (see Table 2). In fact, the lowest value (35\%) of that frequency (cases with $\mathrm{CC}>0.5$ ) is found when the overall height interval of $5-30 \mathrm{~km}$ is considered for correlation fitting. This result indicates that discrepancies between CALIOP and MPL-4 in vertical layering structure are enhanced from $20 \mathrm{~km}$ up, likely due to a decrease of the SNR for both lidars systems at those altitudes. However, PSC formation occurs indeed more frequently at altitudes lower than those heights. Therefore, these results represent a relatively good agreement for the PSC volume linear depolarization ratio $\delta^{\mathrm{V}}$ between MPL-4 and CALIOP profiles.

Regarding the dependence of the correlation between lidar data sets on the distance of the CALIPSO overpass from Belgrano II station, that frequency (cases with CC $>0.5$ ) for all three 2009-2011 winters, and individually for 2009, 2010 and 2011 wintertime periods is shown in Fig. 5 as a function of the four predominant distance ranges. Results confirm a weak dependence on that distance for all the years, in general. Indeed, no large differences are unexpectedly observed in the correlation between both vertical structures of depolarization when the CALIPSO ground-track is just at a few kilometers from the station (at $0-10 \mathrm{~km}, \mathrm{D} 1$ ), showing a 


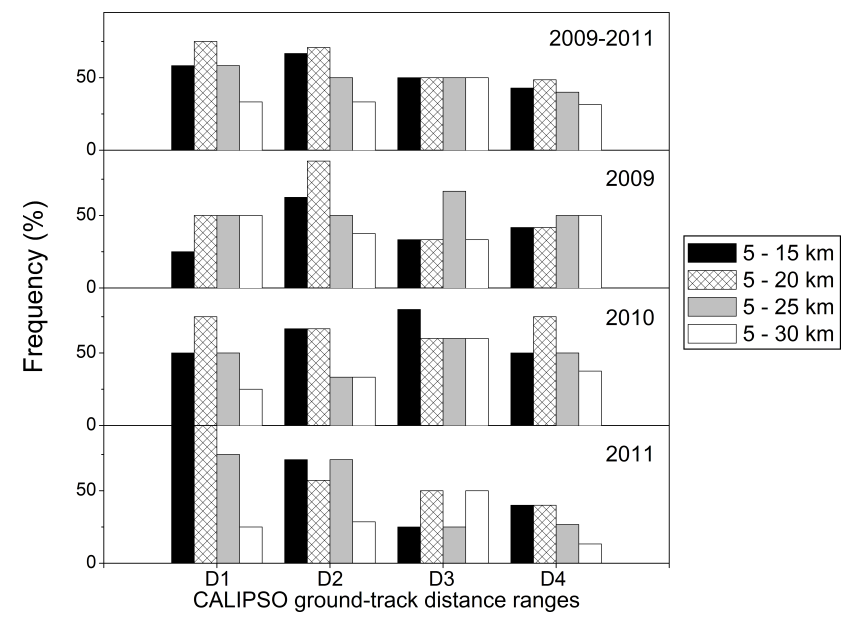

Fig. 5. Frequency (\%) of correlation coefficients (CC) higher than 0.5 for four fitting height intervals (see legend) for the four predominant CALIPSO ground-track distances from Belgrano II station (D1: < $10 \mathrm{~km}, \mathrm{D} 2:$ 20-30 km, D3: 45-55 km, and D4: 70-90 km) examined in this work during all three years (2009-2011), and individually for 2009, 2010 and 2011 wintertime periods.

frequency of $75 \%$ with $\mathrm{CC}>0.5$, and with respect to rather large separations (at $70-90 \mathrm{~km}, \mathrm{D} 4)$ with a lower frequency of $49 \%$ (see Fig. 5). Actually, these results indicate that MPL-4 depolarization observations would reflect relatively well the PSC field that CALIOP can detect at large distances from the ground-based station.

\subsubsection{Comparison analysis II: mean differences $(\Delta)$ and their root mean square (RMS) values}

In order to complement that previous comparison analysis, the differences, $\Delta=\delta^{\mathrm{MPL}}-\delta^{\mathrm{CAL}}$, between MPL- 4 and CALIOP $0.5-\mathrm{km}$ averaged profiles, $\delta^{\mathrm{MPL}}$ and $\delta^{\mathrm{CAL}}$, respectively, are calculated for the four predominant CALIPSO distance ranges: $<10 \mathrm{~km}$ (D1), 20-30 km (D2), 45-55 km (D3) and 70-90 km (D4). Mean differences between those profiles fulfilling that their corresponding CALIPSO separation is within a given distance range, $\Delta_{\mathrm{d}}(z)$, together with their root mean square (RMS) values are shown in Fig. 6. In general, slight discrepancies are observed for the mean differences and RMS values depending on the CALIPSO separation (see Fig. 6). Results indicate that $\Delta_{\mathrm{d}}(z)$ are mostly negatives with a tendency to values close to zero or even positives at the $20-25 \mathrm{~km}$ height interval, reaching larger negatives values with higher data dispersion at altitudes from $25 \mathrm{~km}$ up. In addition, RMS values are no larger than 0.3 in overall, being lower than 0.15 at altitudes up to $20 \mathrm{~km}$, in general, for all the distance ranges. This result shows that only a slight data dispersion is found at high altitudes. Variations of the RMS values are rather small depending on the distance range.

Moreover, these $\Delta_{\mathrm{d}}$ profiles have been averaged, for simplicity, in 5-km thick layers, $\Delta_{\mathrm{d}}^{5-\mathrm{km}}$, in order to examine the
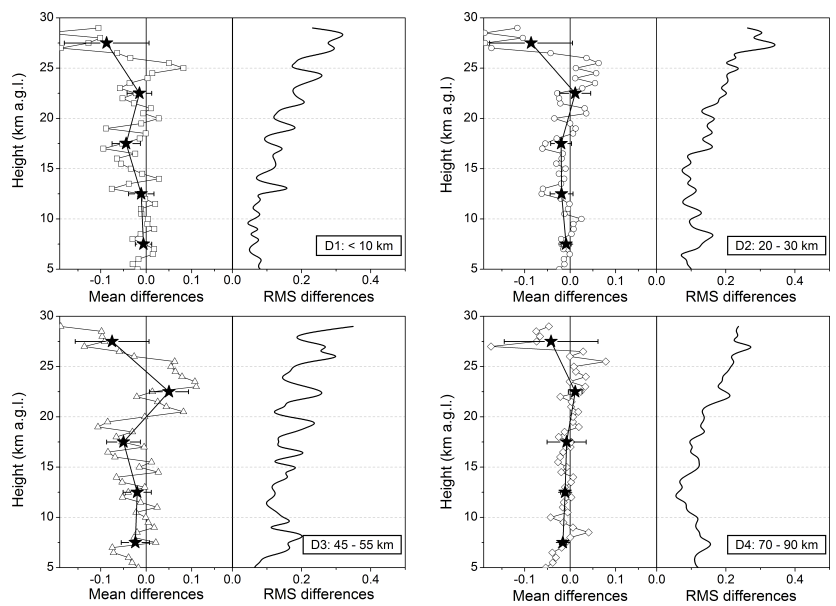

Fig. 6. Mean differences $\left(\Delta=\delta^{\mathrm{MPL}}-\delta^{\mathrm{CAL}}\right)$ (open symbols, left) and their RMS values (solid line, right) for the four predominant CALIPSO ground-track distance ranges (from left to right, and from top to bottom, respectively): < $10 \mathrm{~km}$ (D1), 20-30 km (D2), 45$55 \mathrm{~km}$ (D3) and 70-90 km (D4). 5-km averaged mean differences (black stars, with their SD errors) are also shown.

behaviour of these mean differences $\Delta_{\mathrm{d}}$ in relation with the CALIPSO ground-track distances (data also shown in Fig. 6 as black stars). As previously, slight discrepancies are observed at all the distance ranges, and a predominance of negative values is found among all the 5-km averaged layers. Similar height-averaged values are obtained at altitudes up to $20 \mathrm{~km}$, being their mean value $-0.011 \pm 0.006$ within all the distance ranges. In addition, absolute $\Delta_{\mathrm{d}}^{5-\mathrm{km}}$ values are no higher than 0.1 , but with a larger data dispersion at altitudes higher than $20 \mathrm{~km}$. However, $\Delta_{\mathrm{d}}$ (in absolute value) unexpectedly seems to slightly decrease as distance increases up to $70-90 \mathrm{~km}$.

\subsubsection{Comparison analysis III: percentage differences (BIAS)}

This procedure has previously been used for ground-based lidar profiles in comparison with CALIOP data in the case of the tropospheric attenuated backscatter coefficients at middle-latitude regions (Mamouri et al., 2009; Mona et al., 2009). Hence, it is applied for the PSC volume linear depolarization ratio $\delta^{\mathrm{V}}$ for the first time in this work. Both $0.5-\mathrm{km}$ averaged MPL-4 and CALIOP data sets are used to calculate the BIAS (see Eq. 7) as an altitude-dependent parameter obtained for comparison analysis between both lidar data sets.

Due to the large BIAS data dispersion obtained, in general, a determined constraint condition is applied to the BIAS profiles: only BIAS values within a given interval $(-50 \%<$ BIAS $<+50 \%)$ are regarded. This constrained selection is done to evaluate BIAS values with a given realistic significance, ignoring values rather higher than $\pm 50 \%$. From a statistical point of view, a height-averaged BIAS, 
$\mathrm{BIAS}_{z}$, is calculated from the "constrained" profiles, also considering the number of data points in each profile fulfilling that condition. "Constrained" $\mathrm{BIAS}_{z}$ values for all the cases are shown in Table 2 together with their standard deviation (SD), including the percentage of number of data points fulfilling that condition ( $N^{\mathrm{BIAS}}$, in \%) for each case.

Results show that $\delta^{\mathrm{MPL}}$ is in general underestimated with respect to CALIOP $\delta$ CAL values with a clear predominance of negative BIAS $_{z}$ values: $74 \%$ out of those 83 cases available for comparison (see Table 2). In addition, the number of data points fulfilling the constraint $(-50 \%<$ BIAS $<+50 \%)$ condition in average $<N^{\mathrm{BIAS}}>$ is $25 \pm 13 \%$, thus showing a large data dispersion with BIAS values higher than $\pm 50 \%$. Despite this result, mean absolute differences between $\delta^{\mathrm{MPL}}$ and $\delta^{\mathrm{CAL}}$ are no higher than $10 \pm 7 \%$ with respect to CALIOP values with a median value of $9 \%$. It is worth mentioning that the calculated percentage differences, BIAS, are rather large at PSC-free altitudes, mostly in the $5-10 \mathrm{~km}$ height interval, due to relatively low $\delta^{\mathrm{CAL}}$ values close to the molecular one in that region, and as a consequence BIAS considerably increases following Eq. (7). Additional calculations have been performed and BIAS values have been averaged within an smaller height range, from 10 to $20 \mathrm{~km}$, in order to avoid that particular PSC-free region and also altitudes higher than $20 \mathrm{~km}$ with a larger data dispersion (as shown in the previous Sect. 3.2.2). In this case, $71 \%$ of the cases present negatives $\mathrm{BIAS}_{z}$ and $<N^{\mathrm{BIAS}}>=34 \pm 23 \%$, being the mean absolute differences between $\delta^{\mathrm{MPL}}$ and $\delta^{\mathrm{CAL}}$ no higher than a $14 \pm 11 \%$ with respect to CALIOP values with a median value of $11 \%$. These results are in agreement with those values obtained for the mean differences, as expected.

Moreover, likewise the two previous approaches (see Sects. 3.2.1 and 3.2.2), the BIAS dependence on the CALIPSO ground-track distance from Belgrano II station is also evaluated. BIAS values obtained for each year as a function of the four main distance ranges (D1: $<10 \mathrm{~km}$, D2: 20-30 km, D3: 45-55 km, and D4: 70-90 km) are shown in Fig. 7. A predominance of negative values is observed, showing the previously commented $\delta^{\mathrm{MPL}}$ underestimation with respect to $\delta^{\mathrm{CAL}}$. In particular, averaged BIAS on the four distance ranges, $\mathrm{BIAS}_{\mathrm{d}}$, are obtained: $-10 \pm 8 \%,-6 \pm 8 \%$, $-9 \pm 9 \%$ and $-8 \pm 11 \%$, respectively (see Fig. 7). These similar values indicate that the BIAS is independent on CALIPSO separation, with practically no increase in those differences between both lidar data sets as the CALIPSO overpass is far from the station. However, a slightly increasing dispersion of those BIAS values can be observed as the distance increases.

\subsubsection{Comparison analysis of particular cases}

A few cases of particular PSC events are described in more detail below. They depict different comparison features as a function of the CALIPSO ground-track distance from the

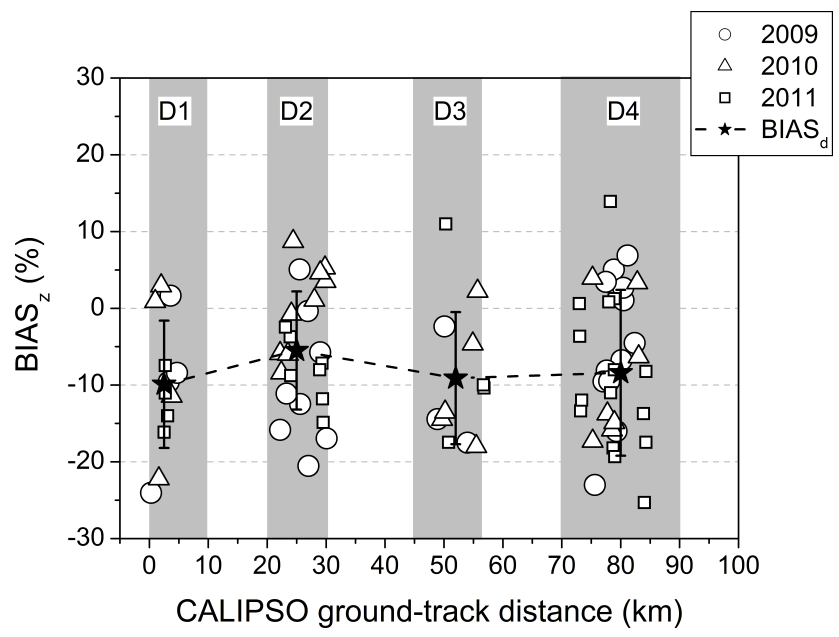

Fig. 7. Height-averaged BIAS, $\mathrm{BIAS}_{z}$, in dependence on the CALIPSO ground-track distance from Belgrano II station for 2009 (circles), 2010 (triangles) and 2011 (squares) wintertime periods. Those averaged values BIAS $_{\mathrm{d}}$ (SD is marked by error bars) on each CALIPSO predominant separation (from D1 to D4) are also shown (black stars).

Belgrano II station (within the four predominant distance ranges).

Figures 8-11 represent simultaneous $0.5-\mathrm{km}$ averaged profiles of the volume linear depolarization ratio $\delta^{\mathrm{V}}$ for MPL-4 $\left(\delta^{\mathrm{MPL}}\right.$, full circles) and CALIOP $\left(\delta^{\mathrm{CAL}}\right.$, open triangles), together with the corresponding differences, $\Delta=\delta^{\mathrm{MPL}}-\delta^{\mathrm{CAL}}$ (as shown by black stars), found between both lidar $\delta^{\mathrm{V}}$ profiles depending on the four predominant (D1 to D4) CALIPSO distance ranges, respectively. PSC events correspond to those cases with high/moderate and low CC values (left and right panels in each figure, respectively) (see Sect. 3.2.1 and Table 2).

In particular, the PSC event observed on 1 July 2009, when the CALIPSO ground-track overpass is at $3.6 \mathrm{~km}$ distance from Belgrano II station (see Fig. 8, left), presents a high correlation coefficient $(0.91)$ between both lidar $\delta^{\mathrm{V}}$ data sets for a fitting height range of 5-25 km, decreasing as height increases (see Table 2). $\delta^{\mathrm{V}}$ values higher than 0.2 are obtained from around 18.5 up to $22.5 \mathrm{~km}$ height; this result is also in agreement with those stratospheric temperatures lower than $T^{\text {PSC-II }}$ present in the same height range (see Fig. 4 and Sect. 2.2.1 for more detail). However, PSC depolarization features observed on 25 September 2009 (see Fig. 8, right) by both lidar systems present highly uncorrelated vertical layering structures as indicated by a low CC value (0.12), despite that the CALIPSO separation is within the same distance range as the former case (see Table 2). In addition, absolute differences are mostly lower than 0.15 on 1 July 2009 (case with high CC) as compared to those found on 25 September 2009 (low CC) with a higher dispersion of those differences. Height-averaged values of those MPL-4/CALIOP 

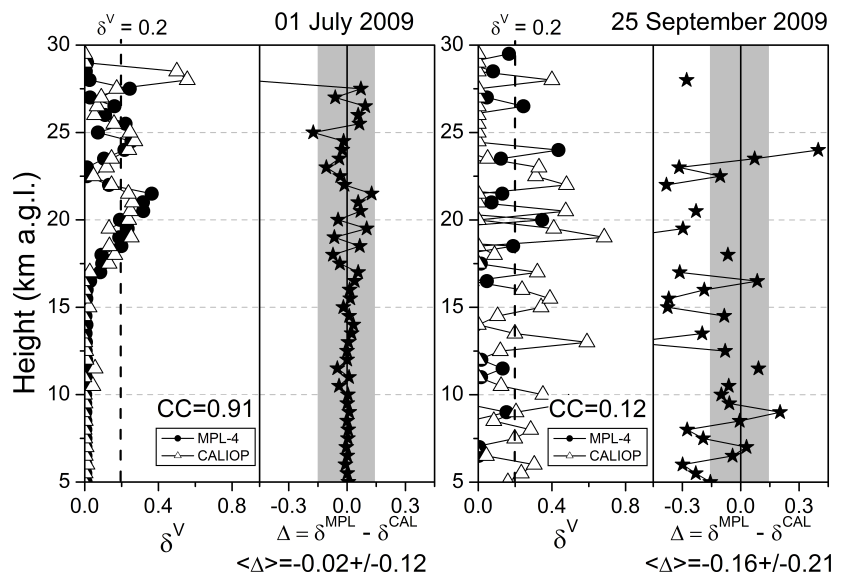

Fig. 8. Simultaneous $0.5-\mathrm{km}$ averaged profiles of the volume linear depolarization ratio $\delta \mathrm{V}$ for MPL-4 (full circles) and CALIOP (open triangles), and the differences $\Delta=\delta^{\mathrm{MPL}}-\delta^{\mathrm{CAL}}$ (black stars) found between both lidar $\delta^{\mathrm{V}}$ profiles for CALIPSO ground-track distances $<10 \mathrm{~km}$ (D1 distance range) from Belgrano II station. PSC events correspond to those cases with a high/moderate and low $\mathrm{CC}$ values as observed, respectively, on 1 July 2009 (left) and 25 September 2009 (right). A height-averaged $\Delta$ value $(<\Delta> \pm \mathrm{SD})$ is also shown in each case.

differences $\langle\Delta\rangle$ were also calculated: $-0.02 \pm 0.12$ and $-0.16 \pm 0.21$ are found on 1 July 2009 and 25 September 2009, respectively. As previously stated, these negative differences indicate an underestimation of the MPL-4 depolarization with respect to that for CALIOP, being this underestimation more severe for the case with a low correlation between both lidar data sets, i.e., on 25 September 2009 (see Fig. 8).

The PSC events observed on 23 August 2011 and 3 July 2010 are the cases presenting a high $(C C=0.75)$ and low $(\mathrm{CC}=0.20)$ correlation, respectively, within a fitting height range of $5-25 \mathrm{~km}$ between MPL-4 and CALIPSO $\delta^{\mathrm{V}}$-profiles (see Fig. 9, left and right, respectively) when the CALIPSO ground-track overpass is within the D2 distance range $(20-30 \mathrm{~km})$ from the ground-based station. As previously, the correlation decreases as height increases (see Table 2), with a more severe decrease on 3 July 2010 (low CC). In particular, $\delta^{\mathrm{V}}>0.2$ values are mainly found from 9 up to $16.5 \mathrm{~km}$ height (a cirrus/PSC overlapping at $9-10 \mathrm{~km}$ height range is present) and also at altitudes from 19 up to $24 \mathrm{~km}$ height on 23 August 2011 (see Fig. 9, left), in contrast with those found on 3 July 2010 (see Fig. 9, right) with the overall $\delta^{\mathrm{V}}<0.2$, except for two spike-like PSC features at $15.5 \mathrm{~km}$ and $18 \mathrm{~km}$ height reported by CALIOP data. In both cases, absolute differences are mostly lower than 0.15 up to $25 \mathrm{~km}$ height. Height-averaged values $\langle\Delta\rangle=-0.06 \pm 0.16$ and $-0.03 \pm 0.16$ are found on 23 August 2011 and 3 July 2010, respectively. That previously observed MPL- $4 \delta^{\mathrm{V}}$ underestimation is also found, but with similar values for both cases (see Fig. 9).

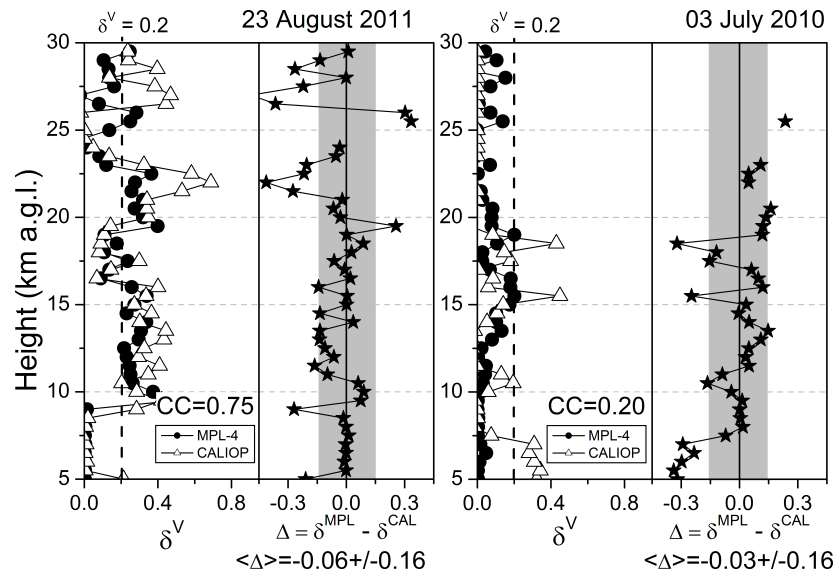

Fig. 9. The same as for Fig. 8, but for the CALIPSO D2 distance range (20-30 km). PSC events correspond to those cases with a high/moderate and low $\mathrm{CC}$ values as observed, respectively, on 23 August 2011 (left) and 3 July 2010 (right).

Particular cases when the CALIPSO ground-track separation is fairly far from the Belgrano II station (within the D3 distance range: $45-55 \mathrm{~km}$ ) are selected, corresponding to PSC events observed on 22 August 2011 and 12 July 2010 . These two cases present moderate $(0.60)$ and low (0.31) correlation coefficients, respectively, within a fitting height range of 5-25 km (see Table 2) between MPL4 and CALIPSO $\delta^{\mathrm{V}}$-profiles (see Fig. 10, left and right, respectively). A decreasing of the degree of correlation is also observed, as in those previous cases, when a larger height interval is examined. In particular, vertical $\delta^{\mathrm{V}}$ structures are well correlated up to altitudes lower than $25 \mathrm{~km}$ in both cases, but a more severe disagreement is observed for the low CC case (12 July 2010, see Fig. 10, right), as expected. In addition, $\delta^{\mathrm{V}}>0.2$ values are mainly found from 11 up to $23 \mathrm{~km}$ height on 22 August 2011 (see Fig. 10, left), being mostly close to 0.2 on 12 July 2010 (see Fig. 10, right), except for several spike-like PSC features centered at 19.5, 22.5 and $27 \mathrm{~km}$ heights as observed by CALIOP. In both cases, absolute differences are mostly lower than 0.15 up to $20 \mathrm{~km}$ height. Height-averaged values $\langle\Delta\rangle=-0.02 \pm 0.16$ and $-0.06 \pm 0.23$ are found on 22 August 2011 and 12 July 2010, respectively. As aforementioned, a MPL- $4 \delta^{\mathrm{V}}$ underestimation is also obtained for both cases, but presenting a higher dispersion for the lower correlated case (see Fig. 10).

Figure 11 shows those PSC features observed on 31 July 2010 (left) and 22 June 2011 (right) presenting high (0.86) and low (0.27) correlation coefficients, respectively, within a fitting height range of 5-25 km (see Table 2). These cases correspond to rather far CALIPSO ground-track separations from the Belgrano II station (D4 distance range: $70-90 \mathrm{~km})$. In general, the degree of correlation is also reduced at altitude ranges higher than $25 \mathrm{~km}$, as previously observed, being more notably observed for the low CC case 

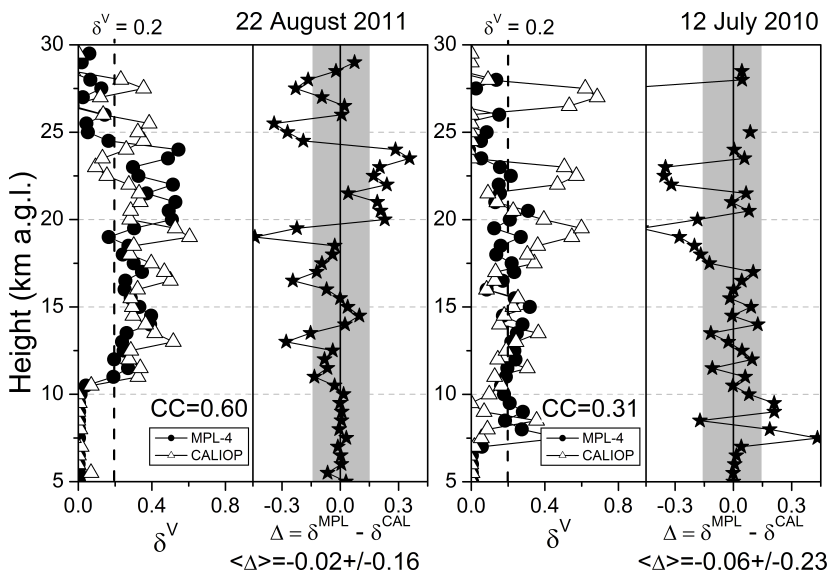

Fig. 10. The same as for Fig. 8, but for the CALIPSO D3 distance range (45-55 km). PSC events correspond to those cases with a high/moderate and low $\mathrm{CC}$ values as observed, respectively, on 22 August 2011 (left) and 12 July 2010 (right).

(22 June 2011, see Fig. 11, right), where the correlation drops from $20 \mathrm{~km}$ up. In particular, $\delta^{\mathrm{V}}>0.2$ values are mainly found from around 9 up to $20 \mathrm{~km}$ height on 31 July 2010 (see Fig. 11, left), where a cirrus/PSC overlapping at 8$10 \mathrm{~km}$ height range is present. Besides, a spike-like PSC feature centered at around $26 \mathrm{~km}$ height can be only observed by CALIOP data with $\delta^{\mathrm{V}}$ values rather higher than $0.2 . \delta^{\mathrm{V}}$ values are mostly around 0.2 on 22 June 2011 (see Fig. 11, right), presenting also two spike-like PSC features with $\delta^{\mathrm{V}}>0.2$ centered at around 15 and $17.5 \mathrm{~km}$ heights by CALIOP data, and one more at around $25 \mathrm{~km}$ height detected by both lidars. Absolute differences are mainly lower than 0.15 up to $25 \mathrm{~km}$ height on the high CC case, but not for the low $\mathrm{CC}$ case with a higher number of points outside this \pm 0.15 range. $\langle\Delta\rangle$ values are similar to those obtained for the previous cases corresponding to CALIPSO smaller separations. In particular, $-0.03 \pm 0.21$ and $-0.08 \pm 0.18$ are found on 31 July 2010 and 22 June 2011, respectively. As for the other cases, a MPL- $4 \delta^{\mathrm{V}}$ underestimation is also obtained for both of these cases (see Fig. 11).

These results indicate that particular PSC features are observed when individual simultaneous cases are examined. However, in general, a high degree of correlation between the vertical $\delta$ V structures from MPL-4 and CALIOP data sets is found for those cases presenting large $\delta^{\mathrm{V}}$ values. In addition, the correlation decreases at altitudes higher than $25 \mathrm{~km}$. Moreover, absolute differences between both lidar data sets are lower than 0.15 at altitudes up to $20 \mathrm{~km}$, in general, for the high CC cases; higher data dispersion with values outside this range is found for those other low CC cases. In particular, height-averaged $\Delta$ values are similar independently on the CALIPSO ground-track distance from the station. A generalized underestimation of the MPL-4 depolarization with respect to that for CALIOP is obtained, as expected (see previous Sects. 3.2.1-3.2.3).

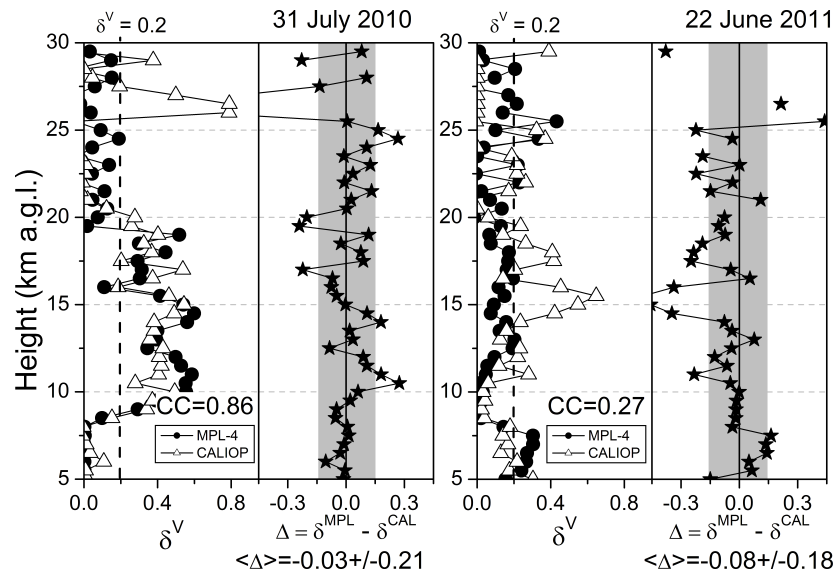

Fig. 11. The same as for Fig. 8, but for the CALIPSO D4 distance range (70-90 km). PSC events correspond to those cases with a high/moderate and low $\mathrm{CC}$ values as observed, respectively, on 31 July 2010 (left) and 22 June 2011 (right).

\section{Summary and conclusions}

This study appears as a first application of the lidar depolarization technique to Antarctic PSC detection and identification by using an improved version (MPL-4) of the standard NASA/Micro Pulse Lidar. In particular, this work represents a significant advance on PSC-type discrimination studies by using MPL- $4 \delta^{\mathrm{V}}$ data.

Calibration parameters for suitable MPL- $4 \delta$ V retrievals have been calculated from MPL-4 measurements. These calibrated $\delta^{\mathrm{V}}$ profiles have been compared with coincident CALIPSO data as a reference during 2009-2011 austral winters, from May to September periods, over Belgrano II station (Argentina, $77.9^{\circ} \mathrm{S} 34.6^{\circ} \mathrm{W}, 256 \mathrm{~m}$ a.s.l.). Coincident observations are referred to simultaneous measurements between both lidar systems within two hours around the closest CALIPSO overpass to the Belgrano II station. That is, four predominant distance ranges between the CALIPSO groundtrack and the station have been selected in order to examine the dependence of the degree of agreement between both lidar $\delta^{\mathrm{V}}$-profile data sets on the distance from the Belgrano II station. Three analysis procedures for $\delta^{\mathrm{V}}$-profile comparison between both lidar data sets have been presented.

Correlation analysis shows that $59 \%$ out of all the comparison cases present $\mathrm{CC}$ values higher than 0.5, at least in the altitude range from 5 to $20 \mathrm{~km}$. This frequency (number of cases with $\mathrm{CC}>0.5$ ) decreases down to $35 \%$ when the overall height interval of $5-30 \mathrm{~km}$ is considered for correlation fitting. This indicates that discrepancies between CALIOP and MPL-4 in vertical layering structure are enhanced from $20 \mathrm{~km}$ up, likely due to a decrease of the SNR for both lidar systems at those altitudes. However, PSC formation occurs indeed more frequently at altitudes lower than those heights. Hence, a relatively good agreement is found between both ground-based MPL-4 and space-borne CALIOP profiles of 
the volume linear depolarization ratio $\delta^{\mathrm{V}}$ for PSC events, once the MPL- 4 depolarization calibration parameters are applied. Moreover, no large differences are unexpectedly observed in the correlation analysis between both vertical depolarization structures when the CALIPSO ground-track is just at a few kilometers from the station, showing a frequency of $75 \%$ with $\mathrm{CC}>0.5$, and with respect to rather large separations with a lower frequency $(49 \%)$.

Regarding the differences between both lidar $\delta^{\mathrm{V}}$-profile data sets, two related variables are analysed: the mean differences, $\Delta$, within a given CALIPSO distance range; and the percentage differences, BIAS (see Eq. 7), since, despite its relation with the former $\triangle$, BIAS is a parameter also used in profiling comparisons between CALIOP and other groundbased lidar systems.

Slight discrepancies are observed for the mean differences between those $\delta^{\mathrm{V}}$ profiles depending on the CALIPSO separation. Mean differences $\Delta$ are mostly negatives in the overall height interval, with higher data dispersion at altitudes from $25 \mathrm{~km}$ up. In addition, absolute $\Delta$ values are no higher than 0.1 in average, being lower than 0.05 at altitudes up to $25 \mathrm{~km}$, with RMS values no larger than 0.3 , in general, for all the distance ranges. The other comparison parameter, BIAS, seems to be a less robust indicator of the degree of agreement for lidar $\delta^{\mathrm{V}}$ data sets, since rather less than a half of the cases fulfill the selected constraint condition $(-50 \%<$ BIAS $<+50 \%)$, showing a large data dispersion with absolute percentage differences higher than $50 \%$. This is related to the fact that BIAS is rather large when relatively low $\delta^{\mathrm{CAL}}$ values are present within a given CALIPSO profile (as, for instance, those at PSC-free altitudes), and as a consequence, BIAS considerably increases (see Eq. 7), exceeding the percentage values of that supposed constraint condition. In addition, that previously observed predominance of negative values is also found indicating a generalized $\delta^{\mathrm{MPL}}$ underestimation with respect to CALIOP data. However, absolute differences between $\delta^{\mathrm{MPL}}$ and $\delta^{\mathrm{CAL}}$ are no higher than $10 \pm 11 \%$ in average as compared to CALIOP values. As expected, these results are in agreement with those obtained for the mean differences.

Moreover, the degree of agreement between both lidar $\delta^{\mathrm{V}}$ data sets is moderately dependent on the CALIPSO groundtrack overpass distance from the Belgrano II station, as shown by the results obtained in each one of the comparison analyses carried out: the vertical correlation (CC), and both the mean $(\Delta)$ and percentage (BIAS) differences. That is, no large discrepancies are found when CALIPSO groundtrack distance is as close as $<10 \mathrm{~km}$ as well as rather far (at 70-90 km) from the Belgrano II station.

Actually, these results indicate that MPL-4 depolarization observations would reflect relatively well the PSC field that CALIOP can detect at large distances from the ground-based station. As a consequence, PSC properties would be statistically similar in average over large volumes, and hence the present disagreement found between both the lidar $\delta^{\mathrm{V}}$ data sets would be likely related to be dominated by small spatial PSC inhomogeneities along the CALIPSO separation from the station. This statement is based on the fact that Belgrano II is a station located well inside the polar vortex during almost all the wintertime period. Indeed, the Antarctic polar vortex is quite stable to allow determined thermodynamic conditions leading to a very low variability of the PSC field, and in their properties.

Therefore, a further study, out of the scope of this work, on the correlation between the PSC features and the variability of both the polar potential vorticity and the stratospheric temperature fields would provide an understanding on what the observed discrepancies are really based on. In addition, a detailed ongoing 3-yr statistical analysis of PSC occurrence over Belgrano II station in terms of both the backscattering, $R$, and volume linear depolarization, $\delta^{\mathrm{V}}$, ratios from MPL-4 measurements would complete these studies. This will include a PSC-type discrimination assessment over Belgrano II station, a station well inside the Antarctic polar vortex.

Finally, it is worth mentioning these results are useful for PSC detection and classification in both polar regions by using this kind of micro pulse lidar that operates in full-time continuous mode, providing a more complete evolution of the PSC field on a daily basis.

Acknowledgements. This work has been supported by the Spanish Ministry for Science and Innovation (MICINN) under grant CGL2010-20353 (project VIOLIN), the Spanish Ministry of Education (MEC) fellowship EX2009-0700 and the Andalusian Regional Government project P10-RNM-6299. CALIPSO data were obtained from the NASA Langley Research Center Atmospheric Science Data Center. Authors specially thank the DNA/IAA teams at Belgrano II station for their valuable assistance and support in the lidar and radiosounding measurements. Authors also gratefully acknowledge the valuable and useful comments and suggestions provided by three anonymous reviewers.

Edited by: D. Baumgardner

\section{References}

Adriani, A., Massoli, P., Di Donfrancesco, G., Cairo, F., Moriconi, M. L., and Snels, M.: Climatology of polar stratospheric clouds based on lidar observations from 1993 to 2001 over McMurdo station, Antarctica, J. Geophys. Res., 109, D24211, doi:10.1029/2004JD004800, 2004.

Álvarez, J. M., Vaughan, M. A., Hostetler, C. A., Hunt, W. H., and Winker, D. M.: Calibration technique for polarization-sensitive lidars, J. Atmos. Ocean. Tech., 23, 683-699, 2006.

Cairo, F., Di Donfrancesco, G., Adriani, A., Pulvirenti, L., and Fierli, F.: Comparison of various depolarization parameters measured by lidar, Appl. Optics, 38, 4425-4432, 1999.

Campbell, J. R. and Sassen, K.: Polar Stratospheric Clouds at the South Pole from Five Years of Continuous Lidar Data: Macrophysical, Optical and Thermodynamic Properties, J. Geophys. Res., 113, D20204, doi:10.1029/2007JD009680, 2008. 
Campbell, J. R., Hlavka, D. L., Welton, E. J., Flynn, C. J., Turner, D. D., Spinhirne, J. D., Scott, V. S., and Hwang, I. H.: Full-time, eye-safe cloud and aerosol lidar observation at Atmospheric Radiation Measurement program sites: Instruments and data processing, J. Atmos. Ocean. Tech., 19, 431-442, 2002.

Carslaw, K. S., Wirth, M., Tsias, A., Luo, B. P., Dörnbrack, A., Leutbecher, M., Volkert, H., Renger, W., Bacmeister, J. T., Reimer, E., and Peter, T.: Increased stratospheric ozone depletion due to mountain-induced atmospheric waves, Nature, 391, 675-678, 1998.

Córdoba-Jabonero, C., Gil, M., Yela, M., Maturilli, M., and Neuber, R.: Polar Stratospheric Cloud observations in the 2006/07 Arctic winter by using an improved Micro Pulse Lidar, J. Atmos. Ocean. Tech., 26, 2136-2148, 2009.

Fernald, F. G.: Analysis of atmospheric lidar observations: some comments, Appl. Optics, 23, 652-653, 1984

Hanson, D. R. and Mauersberger, K.: Laboratory studies of the nitric acid trihydrate: implications for the south polar stratosphere, Geophys. Res. Lett., 15, 855-858, 1988.

Hostetler, C. A., Liu, Z., Reagan, J., Vaughan, M., Winker, D., Osborn, M., Hunt, W. H., Powell, K. A., and Trepte, C.: CALIOP Algorithm Theoretical Basis Document, Calibration and level 1 Data Products, PC-SCI-201, NASA Langley Research Center, Hampton, VA 23681, USA, 2006.

Hunt, W. H., Winker, D. M., Vaughan, M. A., Powell, K. A., Lucker, P. L., and Weimer, C.: CALIPSO Lidar Description and Performance Assessment, J. Atmos. Ocean. Tech., 26, 1214-1228, 2009.

Klett, J. D.: Stable analytic inversion solution for processing lidar returns, Appl. Optics, 20, 211-220, 1981.

Lowe, D. and MacKenzie, A. R.: Polar stratospheric cloud microphysics and chemistry, J. Atmos. Sol.-Terr. Phy., 70, 13-40, 2008.

Mamouri, R. E., Amiridis, V., Papayannis, A., Giannakaki, E., Tsaknakis, G., and Balis, D. S.: Validation of CALIPSO spaceborne-derived attenuated backscatter coefficient profiles using a ground-based lidar in Athens, Greece, Atmos. Meas. Tech., 2, 513-522, doi:10.5194/amt-2-513-2009, 2009.

Marti, J. and Mauersberger, K.: A survey and new measurementsof ice vapor pressure at temperatures between $170 \mathrm{~K}$ and $250 \mathrm{~K}$, Geophys. Res. Lett., 20, 363-366, 1993.

Maturilli, M., Neuber, R., Massoli, P., Cairo, F., Adriani, A., Moriconi, M. L., and Di Donfrancesco, G.: Differences in Arctic and Antarctic PSC occurrence as observed by lidar in Ny-Ålesund $\left(79^{\circ} \mathrm{N}, 12^{\circ} \mathrm{E}\right)$ and McMurdo $\left(78^{\circ} \mathrm{S}, 167^{\circ} \mathrm{E}\right)$, Atmos. Chem. Phys., 5, 2081-2090, doi:10.5194/acp-5-2081-2005, 2005.

Mona, L., Pappalardo, G., Amodeo, A., D’Amico, G., Madonna, F., Boselli, A., Giunta, A., Russo, F., and Cuomo, V.: One year of CNR-IMAA multi-wavelength Raman lidar measurements in coincidence with CALIPSO overpasses: Level 1 products comparison, Atmos. Chem. Phys., 9, 7213-7228, doi:10.5194/acp-97213-2009, 2009.

Pal, S. R. and Carswell, A.I.: Polarization properties of lidar backscattering from clouds, Appl. Optics, 12, 1530-1535, 1973.

Parrondo, M. C., Yela, M., Gil, M., von der Gathen, P., and Ochoa, H.: Mid-winter lower stratosphere temperatures in the Antarctic vortex: comparison between observations and ECMWF and NCEP operational models, Atmos. Chem. Phys., 7, 435-441, doi:10.5194/acp-7-435-2007, 2007.
Pitts, M. C., Thomason, L. W., Poole, L. R., and Winker, D. M.: Characterization of Polar Stratospheric Clouds with spaceborne lidar: CALIPSO and the 2006 Antarctic season, Atmos. Chem. Phys., 7, 5207-5228, doi:10.5194/acp-7-5207-2007, 2007.

Pitts, M. C., Poole, L. R., and Thomason, L. W.: CALIPSO polar stratospheric cloud observations: second-generation detection algorithm and composition discrimination, Atmos. Chem. Phys., 9, 7577-7589, doi:10.5194/acp-9-7577-2009, 2009.

Pitts, M. C., Poole, L. R., Dörnbrack, A., and Thomason, L. W.: The 2009-2010 Arctic polar stratospheric cloud season: a CALIPSO perspective, Atmos. Chem. Phys., 11, 2161-2177, doi:10.5194/acp-11-2161-2011, 2011.

Powell, K., Vaughan, M., Winker, D., Lee, K.-P., Pitts, M., Trepte, C., Detweiler, P., Hunt, W., Lambeth, J., Lucker, P., Murray, T., Hagolle, O., Lifermann, A., Faivre, M., Garnier, A., and Pelon, J.: Cloud - Aerosol LIDAR Infrared Pathfinder Satellite Observations (CALIPSO), Data Management System, Data Products Catalog, Document No: PC-SCI-503, Release 3.2, August 2010, NASA Langley Research Center, Hampton, Virginia, USA, 2010.

Rubin, M. J.: Seasonal variations of the Antarctic tropopause, J. Meteorol., 10, 127-134, 1953.

Sassen, K.: Polarization in Lidar, in Lidar: Range-Resolved Optical Remote Sensing of the Atmosphere, edited by: Weitkamp, C., Optical Sci., Springer Ser., Singapore, 2005.

Sassen, K. and Benson, S.: A midlatitude cirrus cloud climatology from the Facility for Atmospheric Remote Sensing. Part II: Microphysical properties derived from lidar depolarization, J. Atmos. Sci., 58, 2103-2112, 2001.

Schotland, R. M., Sassen, K., and Stone, R.: Observations by lidar of linear depolarization ratios by hydrometeors, J. Appl. Meteorol., 10, 1011-1017, 1971.

Shibata, T., Sato, K., Kobayashi, H., Yabuki, M., and Shiobara, M.: Antarctic polar stratospheric clouds under temperature perturbation by nonorographic inertia gravity waves observed by micropulse lidar at Syowa Station, J. Geophys. Res., 108, 4105, doi:10.1029/2002JD002713, 2003.

Solomon, S.: Stratospheric ozone depletion: a review of concepts and history, Rev. Geophys., 37, 275-316, 1999.

Waugh, D. W. and Polvani, L. M.: Stratospheric polar vortices, in The Stratosphere: Dynamics, Chemistry, and Transport, edited by: Polvani, L. M., Sobel, A. H., and Waugh, D. W., Geophys. Monogr. Ser., 190, 43-57, AGU, Washington, DC, 2010.

Winker, D. M., Hunt, W. H., and McGill, M. J.: Initial performance assessment of CALIOP, Geophys. Res. Lett., 34, L19803, doi:10.1029/2007GL030135, 2007. 